\title{
Potent SARS-CoV-2 neutralizing antibodies selected from a human antibody library constructed decades ago
}

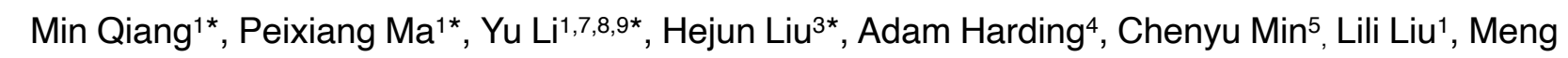
Yuan ${ }^{3}$, Qun $\mathrm{Ji}^{1}$, Pingdong Tao ${ }^{1,7,8,9}$, Xiaojie Shi' ${ }^{1}$, Zhean $\mathrm{Li}^{1}$, Fulian Wang ${ }^{1,7,8,9}$, Yu Zhang ${ }^{7}$, Nicholas C. Wu ${ }^{3}$, Chang-Chun D. Lee ${ }^{3}, X_{\text {Xeyong Zhu }}^{3}$, Javier Gilbert-Jaramillo ${ }^{4}$, Abhishek Saxena ${ }^{1}$, Xingxu Huang ${ }^{7}$, Hou Wang ${ }^{11}$, William James ${ }^{4}$, Raymond A. Dwek ${ }^{6}$, lan A. Wilson ${ }^{3,10, \S}$, Guang Yang ${ }^{1,5, ~}$, Richard A. Lerner2, §

${ }^{1}$ Shanghai Institute for Advanced Immunochemical Studies, ShanghaiTech University, Shanghai 201210, China.

2 Department of Chemistry, The Scripps Research Institute, La Jolla, CA 92037, USA.

${ }^{3}$ Department of Integrative Structural and Computational Biology, The Scripps Research Institute, La Jolla, CA 92037, USA.

${ }^{4}$ Sir William Dunn School of Pathology, University of Oxford, Oxford, OX13RE, UK.

${ }^{5}$ Velox Pharmaceuticals, Changzhou 213000, China.

${ }^{6}$ Oxford Glycobiology Institute, Department of Biochemistry, South Parks Road, Oxford OX1 3QU, UK.

${ }^{7}$ School of Life Science and Technology, ShanghaiTech University, Shanghai 201210, China.

8 Institute of Biochemistry and Cell Biology, Shanghai Institutes for Biological Sciences, Chinese Academy of Sciences, Shanghai 200031, China.

9 University of Chinese Academy of Sciences, Beijing 100049, China.

${ }^{10}$ The Skaggs Institute for Chemical Biology, The Scripps Research Institute, La Jolla, CA 92037, USA.

${ }^{11}$ ShOx Science Limited, Shanghai 200135, China.

*These authors contributed equally to this work.

§Correspondence: wilson@scripps.edu (I.A.W.), yangguang@shanghaitech.edu.cn (G.Y.), rlerner@scripps.edu (R.A.L.) 


\section{$31 \quad$ ABSTRACT}

32 Combinatorial antibody libraries not only effectively reduce antibody discovery to a

33 numbers game, but enable documentation of the history of antibody responses in an

34 individual. The SARS-CoV-2 pandemic has prompted a wider application of this technology to meet the public health challenge of pandemic threats in the modern era. Herein, we used a combinatorial human antibody library constructed 20 years before the COVID-19 pandemic to discover three highly potent antibodies that selectively bind SARS-CoV-2 spike protein and neutralize authentic SARS-CoV-2 virus. Compared to neutralizing antibodies from COVID-19 patients with generally low somatic hypermutation (SHM), these antibodies contain over 13-22 SHMs, many of which are involved in specific interactions in crystal structures with SARS-CoV-2 spike RBD. The identification of these somatically mutated antibodies in a pre-pandemic library raises intriguing questions about the origin and evolution of human immune responses to SARS-CoV-2. 


\section{INTRODUCTION}

45

46

47

The global spread of SARS-CoV-2, a novel coronavirus and cause of the coronavirus disease 2019 (COVID-19), poses an unprecedented health crisis and was declared a pandemic by the World Health Organization on March 11, 2020 (1). To date, over 40 million individuals have been infected with over 1 million deaths (https://covid19.who.int/) with no vaccines or specific antiviral drugs yet approved. Monoclonal antibodies (mAbs) targeting the viral spike glycoprotein (S) have been shown to have excellent neutralization efficacy in previous treatment of SARS, MERS and Ebola infections, and therefore are of particular interest to combat the current pandemic $(2,3)$. Since the COVID-19 outbreak, the spike glycoprotein has been the main target for development of therapeutic mAbs ( 4 , 5). Most neutralizing antibodies (NAbs) bind to the receptor binding domain (RBD) of the S protein (6), although some also bind to the N-terminal domain (NTD) $(7,8)$. NAbs have been derived from multiple sources, including memory B cells from SARS-CoV-2 convalescent patients $(3,9,10)$, previous SARS patients (11), immunized humanized H2L2 mice (12), alpaca nanobodies (13), single domain human antibodies from a preestablished library (14), and phage display antibody libraries $(4,15,16)$.

Antibody generation is an evolutionary process of mutation and selection from the B cell repertoire. The combinatorial antibody library technology allows the same evolutionary process to be performed in vitro as it restores the "fossil record" of an individual's antibody response in a test tube (17). Random coupling of $V_{H}$ and $V_{L}$ sequences in ScFV libraries greatly expands diversity, thereby allowing for selection of novel antibodies with high binding affinity and neutralization efficacy (18-22). 
Here, we report the selection and characterization of three potent SARS-CoV-2 antibodies, S-E6, S-B8 and S-D4, from a pre-pandemic human combinatorial antibody library established in 1999 that target the spike RBD and compete with hACE2 receptor (23). This study provides further evidence that a combinatorial antibody library with an unprecedented diversity can mimic the selection process of natural immunity, permit detection of rare spike-targeting antibodies with higher somatic hypermutation, and allow for selection of binding molecules with chemistries beyond those accessible during in vivo selection.

\section{RESULTS}

\section{Selection of antibodies against SARS-CoV-2 spike RBD}

We constructed and overexpressed the SARS-CoV-2 spike RBD (S-RBD) linked to human $\mathrm{Fc}(h \mathrm{Fc})$ with a thrombin digestion site. After affinity purification, recombinant SARS-CoV-2 S-RBD was biotinylated, immobilized on streptavidin-coated magnetic beads, and panned against a combinatorial scFv antibody phage library containing $10^{11}$ members generated from peripheral blood mononuclear cells (PBMC) of 50 healthy donors in $1999(23,24)$. In the first two rounds, a pH 2.2 glycine- $\mathrm{HCl}$ solution was used to elute antibody-displaying phagemids bound to S-RBD. To enrich for antibodies that compete with hACE2, a "function-guided enrichment" strategy was used in the third round, where recombinant $h A C E 2-E C D$ protein was used to elute S-RBD binding phagemids. After three rounds of panning, S-RBD-specific antibodies were enriched (Figure 1A) and 22 unique antibodies were selected that specifically bound to S-RBD- $h$ Fc (Figure 1B) (24). 
87 Next-generation sequencing of the library revealed that $92 \%$ of human heavy-chain IGHV and $89 \%$ of the light-chain (IGLV and IGKV) germlines were covered, when aligned to the IMGT (international ImMunoGeneTics) database (Supplementary Figure 1), enabling screening of antibodies encoded by diverse germlines.

\section{Selected anti-S-RBD antibodies retain binding to full-length spike}

The scFv antibodies were then converted to full-length monoclonal antibodies (mAbs) by cloning into a human IgG4e1(S228P) vector. HEK293F cells were adapted for expression of combinatorial antibodies that were secreted into culture supernatants (24). Three of the best performing antibodies, S-B8, S-D4 and S-E6, were purified to homogeneity with yields of $8.1,9.6$ and $17 \mathrm{mg} / \mathrm{L}$, respectively, whereas S-RBD- $h F c$ (IgG1) was $58 \mathrm{mg} / \mathrm{L}$ (Supplementary Figures $2 \& 3$ ). To characterize interactions between the anti-S-RBD antibodies and full-length spike, HEK293T cells were transiently transfected with either SARS-CoV-2 spike-P2A-EGFP or SARS spike-P2A-EGFP (24). Flow cytometry (FACS) showed that all three antibodies in full-length-IgG4 format retained their ability to bind fulllength SARS-CoV-2 spike (Figure 2A \& 2D) with no cross-reactivity with SARS-CoV spike (Figure 2B) or non-transfected cells (Figure 2C).

\section{Antibody binding and competition with hACE2-ECD to SARS-CoV-2 S-RBD}

To assess neutralization potential of the mAbs, we investigated their ability to compete with ACE2-ECD for S-RBD binding by ELISA $(15,25)$. S-B8, S-D4 and S-E6 all competed strongly with $h A C E 2-E C D$ in a dose-dependent manner, with $I_{50}$ values of $12.9 \pm 1.5 \mathrm{nM}$, 7.1 $\pm 0.4 \mathrm{nM}$, and $12.2 \pm 0.7 \mathrm{nM}$, respectively (Figure $3 \mathrm{~A}$ ). Kinetic parameters of on-rate $\left(k_{o n}\right)$, off-rate $\left(k_{\mathrm{off}}\right)$, and dissociation constant $\left(\mathrm{K}_{\mathrm{D}}\right)$ for the three antibodies were then 
determined by biolayer interferometry (Figure 3B - 3E). S-B8, S-D4, and S-E6 showed $\mathrm{K}_{\mathrm{D}}$ values of $170 \mathrm{pM}, 10 \mathrm{pM}$ and $110 \mathrm{pM}$, respectively, with S-D4 displaying the highest affinity due to its greatly reduced off-rate (Figure 3C).

We also tested with natural mutants of SARS-CoV-2 spike proteins that have been clinically associated with more severe illness and longer hospital stays. Three mutants, i.e. $\mathrm{D} 215 \mathrm{H}$ (mut 1), S247R (mut 2) and D614G (mut 3), isolated from patients requiring treatment in an intensive care unit (ICU) (26), all displayed similar binding by FACS to SB8, S-D4, and S-E6 (Supplementary Figure 4), indicating their therapeutic potential against natural SARS-CoV-2 spike mutants in severely affected patients.

\section{Inhibition of cell-cell fusion induced by SARS-CoV-2 spike and hACE2}

The S2 subunit of the SARS-CoV-2 spike mediates membrane fusion in hACE2 expressing cells and is essential for virus infection. hACE2 binding to SARS-CoV-2 is stronger than to the SARS-CoV spike (KD of $4.7 \mathrm{nM}$ and $32 \mathrm{nM}$, respectively) (27). To test whether these antibodies could inhibit spike-mediated membrane fusion of cells, we established a cell-cell fusion assay using Vero cells overexpressing hACE2 as target cells, SARS-CoV-2 spike-P2A-EGFP transient transfected HEK293F cells as effector cells, and SARS-CoV spike-P2A-EGFP cells as a negative control (24). Spike-expressing HEK293F cells were mixed with S-B8, S-D4 or S-E6 at $10 \mathrm{nM}$ or $1 \mathrm{nM}$ just before adding to the Vero cells and syncytium formation observed 6 hours later. The SARS-CoV-2 spike induced significant cell-cell fusion as manifested by formation of larger EGFP positive cells, whereas the SARS-CoV spike barely induced syncytium formation (Figure 4A). All three antibodies potently inhibited cell-cell fusion by SARS-CoV-2 at both 10 and $1 \mathrm{nM}$ (Figure 
$1314 \mathrm{~B}, 4 \mathrm{C} \& 4 \mathrm{~F})$. At $10 \mathrm{nM}, \mathrm{S}-\mathrm{D} 4$ and S-E6 showed over $80 \%$ inhibition of cell-cell fusion,

132 which was slightly greater than recombinant S-RBD; S-D4 and S-E6 were more potent

133 than S-B8 at 1 and $10 \mathrm{nM}$ (Figure 4D \& 4E).

134

135

136

137

138

139

140

141

142

\section{Inhibition of SARS-CoV-2 pseudovirus and authentic virus}

To test neutralization against SARS-CoV-2 virus, we assessed the antibodies in a pseudovirus (PSV) infection assay. Pseudotyped particles were pre-incubated with S-B8 and S-D4 (from $200 \mathrm{nM}$ to $200 \mathrm{fM}$ ) and S-E6 (200 nM to $6.3 \mathrm{fM}$ ), followed by infection of HEK293T/hACE2 cells (24). Luciferase activity resulting from infection was determined at $60 \mathrm{~h}$ post transfection. All three antibodies showed potent neutralization against PSV infection in a dose-dependent manner that went to completion. The NT50 values of S-B8, S-D4, and S-E6 in pseudovirus neutralization were determined to be $2.2 \pm 0.2 \mathrm{nM}$, $0.48 \pm 0.03 \mathrm{nM}$, and $0.025 \pm 0.002 \mathrm{nM}$, respectively (Figure $5 \mathrm{~A}$ ) in a $1: 1$ interaction model with HillSlopes near 1.0 (Figure 5B). We next tested antibody neutralization of authentic SARS-CoV-2 virus [BetaCoV/Australia/VIC01/2020; GenBank MT007544.1 (Victoria/01/2020)] (24). Twenty hours after infection, intracellular virus was visualized and quantitated as percent infectivity. S-D4 and S-E6 were capable of fully blocking infection by authentic virus, while S-B8 was less potent (Figure $5 \mathrm{C}$ ) with $\mathrm{NT}_{50}$ values for S-B8, S-D4 and S-E6 of $16 \mathrm{nM}, 0.7 \pm 0.08 \mathrm{nM}$ and $0.25 \pm 0.05 \mathrm{nM}$, respectively (Figure 5D).

\section{S-B8 and S-E6 bind the RBD and sterically block ACE2 binding}

To elucidate the molecular recognition of S-B8 and S-E6 for SARS-CoV-2 S-RBD, x-ray structures of Fab/RBD complexes were determined to 2.25 and $2.70 \AA$, respectively (Supplementary Table 1). Fab S-B8 and S-E6 bind the receptor binding site (RBS) with 
153 different approach angles (Figure 6A) and sterically compete with ACE2 for RBD binding,

154 consistent with the competition assay (Figure 3A). S-B8 interacts mainly using its heavy

155 chain, which contributes $73 \%$ of the buried surface area (BSA, 737 of $\left.1010 \AA^{2}\right)$ (Figure

156 6B) and 12 of 16 polar contacts (Supplementary Table 2). S-E6 predominately uses its

157 light chain, which contributes $63 \%$ of the BSA (530 of $847 \AA^{2}$ ) and 16 of 19 polar contacts

158 (Supplementary Table 2). Light chain dominant interactions are less common in 159 antibodies $(28,29)$.

IgBLAST analysis (30) suggests S-B8 is derived from IGHV3-66, a germline that is highly similar to IGHV3-53 (Supplementary Figure 5). We previously reported that IGHV3-53 antibodies from convalescent patients, with minimal SHM and high potency, have two key germline motifs in $\mathrm{CDRH} 1$ and $\mathrm{CDRH} 2$ that are primarily used for recognition of SARS-CoV-2 S-RBD, namely ${ }_{32} \mathrm{NY}_{33}$ and ${ }_{53} \mathrm{SGGS}{ }_{56}(31,32)$. In addition, two very distinct binding modes (A and B) are observed for IGHV3-53/3-66 antibodies depending on $\mathrm{CDRH} 3$ length (31-33). However, in S-B8, ${ }_{2} \mathrm{NY}_{33}$ in $\mathrm{CDRH} 1$ is mutated to ${ }_{32} \mathrm{SH}_{33}$ and ${ }_{53} \mathrm{SCGS}_{56}\left({ }_{53} \mathrm{TGGT}_{56}\right.$ in COVA2-39) in CDRH2 to ${ }_{53} \mathrm{GDGN}_{56}$ (Supplementary

168 Figures 6 \& 7). Intriguingly, $\mathrm{CDRH} 1$ and $\mathrm{CDRH} 2$, as well as $\mathrm{FRH} 1$, of $\mathrm{S}-\mathrm{B} 8$ still bind to a 169 similar region on SARS-CoV-2 S-RBD to that of binding mode B (Figure 6B) (31). The $170{ }_{32} \mathrm{SH}_{33}$ in S-B8 is part of a type I beta-turn (Figure 6C). $\mathrm{V}_{\mathrm{H}}$ S32 interacts with RBD Q493 171 and its side-chain hydroxyl hydrogen bonds to the $\mathrm{V}_{H}$ T28 carbonyl oxygen. The $\mathrm{V}_{\mathrm{H}} \mathrm{H} 33$ 172 imidazole forms a salt bridge with RBD E484 and a $\pi-\pi$ interaction with $Y 489$. The $V_{H}$ $173{ }_{53} \mathrm{GD}_{54}$ backbone in $\mathrm{CDRH} 2$ also forms two hydrogen bonds with $\mathrm{E} 484$, and $\mathrm{V}_{\mathrm{H}} \mathrm{T}_{28}$ and 174 L31 make four hydrogen bonds with Q493 and S494 (Figure 6C, Supplementary Table 2). 
$175 \mathrm{~F} 486$ in the S-RBD ridge region is buried in a hydrophobic pocket $\left(\mathrm{V}_{\mathrm{H}} \mathrm{W}_{47}, \mathrm{~V}_{\mathrm{H}} \mathrm{I50}, \mathrm{V}_{\mathrm{L}}\right.$

176 Y91, VL L94, VL L96) between the heavy and light chains, while ${ }_{485} \mathrm{GF}_{486}$ and ${ }_{476} \mathrm{GS}_{477}$ on

177 the $R B D$ ridge interact with $V_{H} Y 52$ and $V_{L} Y 27 d$ via $\pi-\pi$ interactions (Figure 6D). Of note,

178 F486 is also buried in a pocket at the heavy-light chain interface in COVA2-39, which is

179 an IGHV3-53 antibody, as well as other antibodies that bind in RBS-B mode (34).

180 Altogether, 19 of 29 S-B8 epitope residues are shared with 19 of 21 COVA2-39 epitope

181 residues, with16 corresponding to ACE2 binding residues (Supplementary Figure 8).

\section{S-E6 interaction with SARS-CoV-2 S-RBD}

S-E6 is an IGHV4-31 antibody. Interestingly, SHM introduces a ${ }_{33} \mathrm{NY}_{34}$ sequence in a 184 similar position to the ${ }_{32} \mathrm{NY}_{33}$ motif in $\mathrm{CDRH} 1$ in IGHV3-53/3-66 antibodies

185 (Supplementary Figure 6) that interact with the same RBD site but in a different orientation compared to ${ }_{32} \mathrm{NY}_{33}$ of IGHV3-53 binding mode $\mathrm{A}$ (34). Nevertheless, $\mathrm{V}_{\mathrm{H}} \mathrm{N} 33$ still hydrogen bonds with RBD A475 carbonyl (Figure 6E), as does $\mathrm{V}_{\mathrm{H}}$ N32 of IGHV3-53 in binding mode $\mathrm{A}$ (Figure $6 \mathrm{~F}$ ). $\mathrm{V}_{\mathrm{H}} \mathrm{Y} 34$ and $\mathrm{V}_{\mathrm{H}} \mathrm{A} 97$ form two hydrogen bonds with $\mathrm{N} 487$ of the S-RBD (Figure 6E), which differ from Y33 in IGHV3-53 antibodies (Figure 6F). F486, along with N487, interact with a hydrophobic pocket formed by $\mathrm{V}_{\mathrm{H}} \mathrm{Y} 34, \mathrm{~A} 97, \mathrm{H} 101$ and I102 of S-E6 and also make $\pi-\pi$ and cation- $\pi$ interactions (Figure 6E). However, the S-E6 light chain contributes the majority of the buried surface with RBD. CDRL2 ${ }_{50} F D Y R_{53}$ interact with the receptor binding motif (RBM) via multiple polar interactions (8 hydrogen bonds and 3 salt bridges) to E484, F490, L492, Q493 and S494 (Figure 6G,

195 Supplementary Table 2). Moreover, VL F50 interacts with a nearby hydrophobic patch 196 formed by L455, F456 and Y489 (Figure 6G), and VL S27, G29, S67 and G68 form five 
hydrogen bonds with R403, N501 and Y505 on the other side of the RBS ridge (Figure $6 \mathrm{H}$, Supplementary Table 2).

\section{SHM residues form specific interactions with the RBD}

Unlike most RBD-targeting neutralizing antibodies isolated from COVID-19 patients which have minimal SHM, the antibodies derived from this combinatorial antibody library are more highly mutated; S-B8 and S-E6 contain 13 and 22 SHM residues, respectively, several of which are in the antibody paratope (Figure 6 and Supplementary Figure 6), including $\mathrm{V}_{\mathrm{H}}{ }_{31} \mathrm{LSH}_{33}, \mathrm{~V}_{\mathrm{H}}{ }_{50} \mathrm{TT}_{51}, \mathrm{~V}_{\mathrm{H}}{ }_{33} \mathrm{GD}_{54}, \mathrm{~V}_{\mathrm{H}} \mathrm{N}_{56}, \mathrm{~V}_{\mathrm{H}} \mathrm{D}_{58}$ and $\mathrm{V}_{\mathrm{L}} \mathrm{L} 94$ in S-B8, and $\mathrm{V}_{\mathrm{H}}$ $\mathrm{N}_{33}, \mathrm{~V}_{\mathrm{L}} \mathrm{V}_{39}, \mathrm{~V}_{\mathrm{L}}{ }_{50} \mathrm{FDYR}_{53}$ and ${ }_{65} \mathrm{TR}_{66}$ in S-E6 (Figure 6, C - G, and Supplementary Figure 6). In summary, several SHM residues appear to be critical for interaction with SARSCoV-2 RBD, despite the antibody libraries being generated 20 years ago, implying the possibility that the eliciting antigen was structurally very similar to the SARS-CoV-2 RBD or there is rare but fortuitous cross-reactivity with another antigen.

\section{Antibody autoreactivity}

To investigate the origin of the three antibodies, a HEp-2 autoreactivity assay was performed. Neither S-D4 nor S-E6 showed a positive signal in the assay, suggesting that they are not derived from auto-immune responses (Supplementary Figure 9, A \& B), whereas S-B8 displayed weak to moderate autoreactivity (Supplementary Figure 9C). We further generated an S-B8 putative germline antibody, by mutating back all of the SHMs in the S-B8 heavy chain to the naïve IGHV3-66 sequence. The mutated antibody showed greater autoreactivity than S-B8 (Supplementary Figure 9D) and no S-RBD binding up to $12.5 \mathrm{nM}$ (Supplementary Figure 10). 


\section{DISCUSSION}

220

221

222

223

224

225

226

227

228

229

230

231

232

233

234

235

236

237

238

239

240

For over a century, serology has been used to document the origin and presence of infectious agents in patients. Classically, serology depends on the actual presence of specific antibody proteins in the blood. Their target is thought to be the infectious agent, and their presence indicates a relatively recent exposure. By contrast, antibody libraries are nucleic acid based, and include genetic material from memory cells. As such, they provide a record of all of the antibodies that an individual has made, irrespective of whether they are currently being produced. This "fossil record" enabled us to discover SARS-CoV-2 neutralizing antibodies induced either by previous infection or from other immune responses. Furthermore, combinatorial antibody libraries typically yield more diverse antibodies with the desired specificity. Here, the presence of many somatic mutations in the antibodies indicates a sustained drive of the immune response to continued presence of a foreign antigen, as occurs during virus replication. Thus, the modern serology detailed here suggests that one of the individuals from whom the library was generated could have been exposed to SARS-CoV-2 or a similar virus.

Although the antibody library used here was established in 1999 before the SARS and COVID-19 pandemics (23), three potent neutralizing antibodies were discovered in this library. Wec et al. (4) identified several S-RBD-directed antibodies that potently crossneutralize SARS-CoV (IC50: 0.004-0.06 $\mu \mathrm{g} / \mathrm{mL}$ to pseudovirus) and SARS-CoV-2 (IC50: 0.05-1.4 $\mu \mathrm{g} / \mathrm{mL}$ to pseudovirus) from memory B cells of a SARS donor. They also found over $80 \%$ of the low affinity SARS and SARS-2 cross-reactive antibodies reacted with one or more of the human coronavirus spike proteins, such as HCoV-NL63, HCoV-229E, 
HCoV-OC43, etc., indicating SARS-CoV infection may have boosted a pre-existing memory B cell response induced by circulating HCoVs (4). Interestingly, the three antibodies, S-B8, S-E6 and S-D4, identified in this study do not cross-react with the SARS spike protein. Moreover, autoreactivity assay in a HEp-2 cell ruled out that S-E6 and SD4 originate from autoimmune responses, whereas S-B8 showed weak to moderate autoreactivity (Supplementary Figure 9, A-C), which was increased in the S-B8 putative germline antibody (Supplementary Figure 9D).

Our structural studies on S-E6 and S-B8 revealed several striking features of these combinatorial antibodies. The primary immune response to viral infection is followed by a secondary response that generates functionally better antibodies, where the binding energy can be refined by somatic hypermutation (18). The secondary immune response is for later encounter of the same antigen, and is the basis of vaccination. In cases of pandemics, such as SARS-CoV-2, avian influenza or Ebola virus, if the infection is not dealt with by the immune system in the first few days, the patient has a high probability of dying, and as a consequence, the immune system will not have enough time to refine the immune response (35). Consistently, neutralizing antibodies isolated from SARSCoV-2 convalescent patients contain only a few amino-acid mutations $(3,8,9,36,37)$. that may be a result of weak B cell stimulation due to rapid viral clearance. Neutralizing antibodies from convalescent patients may then possibly not be fully refined (matured) (36). In comparison, S-B8 and S-E6 exhibited much higher SHM, many of which are involved in specific interactions with SARS-CoV-2 RBD (S-RBD). Nine of 13 SHM residues in S-B8 and eight of 22 in S-E6 are located in the antibody-antigen interface 
263 (Supplementary Figure 6). While some of these SHM residues only use their peptide 264 backbone, others rely on specific side chains for S-RBD binding (Figure 6, C, D, E \& G). 265 Interestingly, $\mathrm{SHM}$ in $\mathrm{CDRH} 1$ of $\mathrm{S}-\mathrm{E} 6$ generates a ${ }_{33} \mathrm{NY}_{34}$ sequence that is similar to the ${ }_{32} \mathrm{NY}_{33}$ motif in IGHV3-53/3-66 antibodies, which are the most frequent germlines used in targeting the S-RBD, indicative that the combinatorial antibody library and the maturation process can yield alternate antibody solutions (Supplementary Figure 6). However, it is unclear how these SHM residues could have been raised specifically to the SARS-CoV2 S-RBD, since the library was generated long before the SARS-CoV-2 pandemic. Thus,

271 these findings raise fascinating questions about the original antigen(s) that elicited S-B8 272 and S-E6.

The unnaturally paired antibodies in a combinatorial scFv antibody library also allow one to identify other alternative solutions with high binding affinity and efficacy (18). Rare germline antibodies can then potentially be enriched during the iterative affinity panning,

276 as for example for S-E6, which is an IGHV4-31 antibody rarely seen in neutralizing antibodies from convalescent patients (Supplementary Figure 11).

A general question posed by these studies is whether therapies based on the vast number of starting antibodies in combinatorial libraries could be more powerful than the antibodies generated in vivo during the limited time available for affinity-based antibody 281 evolution and selection in the setting of an acute and potentially lethal infection. This also 282 has direct relevance in the clinical setting, where a major concern in antibody therapy is 283 the high mutation rate of viral spike proteins, which can render prior highly specific 284 antibodies unable to recognize or neutralize mutant viruses. Mixtures of antibodies 
285 targeting distinct epitopes can be used to overcome such immune escape (38).

286 Antibodies identified from combinatorial libraries with high SHM and rare germline

287 derivation, in combination with antibodies from convalescent patients, or with

288 convalescent plasma, could provide yet another therapeutic option and a potential

289 antidote to immune escape. Knowledge of the evolution of immune response in terms of

290 the interactions of neutralizing antibodies and their binding epitopes on SARS-CoV-2 also

291 provide a blueprint for next-generation vaccine design.

292 Since a complete antibody repertoire of an individual is the starting reservoir of all

293 possibilities, one can also learn much more about the origins and evolution of an immune

294 response against viral challenge when it is studied (18). The observation of highly potent

295 neutralizing antibodies from a library of "healthy" donors before the COVID-19 pandemic

296 could also indicate possible prior exposure of a donor(s) to a similar coronavirus 20 years

297 ago. However, whether these antibodies are a consequence of background immunity

298 remains to be elucidated. Notwithstanding, we are not unaware of the potential 299 implications of such findings from libraries made decades ago concerning the origin of 300 the virus currently circulating.

301 MATERIALS AND METHODS

\section{Cell culture}

303 The Vero cell line (ATCC® $\mathrm{CCL}-81^{\mathrm{TM}}$ ) was maintained in a DMEM/F-12k media (Gibco, 304 \#C11330500CP) containing 10\% (v/v) FBS (Gibco, \#1600074). The FreeStyle ${ }^{\text {TM }}$ 293-F 305 (HEK 293F, ThermoFisher Scientific, \#R79007) cell line was cultured in a Freestyle 293 
expression media (ThermoFisher Scientific, \#12338026). For establishing the HEK293T/hACE2 stable cell line, HEK293T cells (ATCC ${ }^{\circledR}$ ACS- $4500^{\mathrm{TM}}$ ) were transiently transfected with hACE2 fusion BFP encoding PB510 plasmid using PiggyBac Transposon System (System Biosciences, PB210PA-1), followed by addition of $2 \mu \mathrm{g} / \mathrm{mL}$ puromycin 6 h post-transfection. The resulting cells were kept in puromycin-containing media for an extra 2 days. Positive cells with BFP expression were sorted by a flow cytometry instrument (BD FACS Aria III). The sorted cells with overexpressed hACE2 were expanded and cultured in a DMEM media (Gibco, \#10566016) supplemented with $10 \%$ FBS $(\mathrm{v} / \mathrm{v})$ and $10 \mu \mathrm{g} / \mathrm{mL}$ puromycin.

\section{Expression and purification of recombinant SARS-CoV-2 spike RBD, human ACE2}

\section{and antibodies}

The DNA sequences of codon-optimized SARS-CoV-2 spike Receptor Binding Domain (S-RBD) and human ACE2 extracellular domain (hACE2-ECD) were cloned into a pFuseFc expression vector (Invivogen). A thrombin cleavage sequence was inserted between RBD and Fc to generate a cleavable human Fc tag for future studies. The SARS-CoV-2 S-RBD- $h F c$ and $h A C E 2-E C D-m F c$ proteins were heterologously expressed in HEK293F cells by transient transfection and cultured for 4 days, then purified by Mabselect columns (Cytiva, \#17-5199-01). Briefly, cell media with secreted Fc tagged recombinant proteins, S-RBD- $h F c$ and $h$ ACE2-ECD- $m F c$, were loaded onto a Mabselect column that was prewashed and equilibrated with a PBS buffer ( $150 \mathrm{mM} \mathrm{NaCl}, 20 \mathrm{mM}$ sodium phosphate, $\mathrm{pH}$ 7.2), and eluted using a pH 3.4 citrate acid buffer.

DNA sequences for the variable regions of the combinatorial antibodies were cloned 
328 into a full-length human lgG4 mutant construct (S228P) and expressed in HEK293F cells

329 for 4 days and further purified by Mabselect chromatography. Purified recombinant 330 proteins and antibodies were buffer-exchanged into a PBS buffer using centrifugal

331 concentrators.

\section{Function-guided phage panning}

333 SARS-CoV-2 S-RBD specific scFv antibodies were selected from a combinatorial human 334 monoclonal ScFv antibody phage library (1011 members) after two rounds of affinity enrichment against the biotinylated S-RBD protein immobilized on the streptavidin-coated

336 magnetic beads (Pierce, \#21925), followed by a third round of competitive panning vs.

337 hACE2-ECD protein. Briefly, phagemid (displaying the antibody library) binding to the

338 antigen (S-RBD) was enriched at each cycle and eluted with Glycine- $\mathrm{HCl}(\mathrm{pH} 2.2)$ in the phagemids for the next round of panning. To determine hACE2 competitive antibodies, a kinetic competitive panning method was adopted in the third round panning. Instead of the conventional $\mathrm{pH} 2.2$ buffer, an elution buffer containing a saturated concentration of hACE2-ECD protein (200 nM; for S-RBD and hACE2-ECD binding, $\mathrm{EC}_{80}=80 \mathrm{nM}$ ) was used to elute the phagemids twice. After three iterations, 96 positive colonies were selected and analyzed by phage ELISA as described (39). All of the positive clones were sequenced using Sanger sequencing. Both the DNA and protein sequences of CDR3 
Avidin (Pierce, \#21121) was diluted to a final concentration of $2 \mathrm{ng} / \mu \mathrm{L}$ in a PBS buffer (Sigma, \#C3041). The resulting avidin solution was used to coat the 96-half well plates (25 $\mu \mathrm{L} /$ well) at $4{ }^{\circ} \mathrm{C}$ overnight. The coated plates were washed once with the PBS buffer (150 $\mu \mathrm{L} /$ well) followed by the addition and incubation of $25 \mu \mathrm{L}$ biotinylated SARS-CoV-2 S-RBD- $h$ Fc solution $(2 \mathrm{ng} / \mu \mathrm{L})$ in each well at room temperature for $1 \mathrm{~h}$. The PBST (PBS containing $0.05 \%$ Tween-20) buffer alone and the $h \mathrm{Fc}$ solution $(2 \mathrm{ng} / \mu \mathrm{L})$ were used as the background and negative controls, respectively. After removal of the incubation solution, the resulting plates were rinsed once using the PBST buffer and incubated with a blocking solution containing $5 \%$ milk (v/v) in PBST (150 $\mu \mathrm{L} /$ well) at $37^{\circ} \mathrm{C}$ for $1 \mathrm{~h}$. After blocking and PBST washing (once), $50 \mu \mathrm{L}$ of phagemid-containing XL1-Blue culture medium supernatants (by centrifuging the third round panning output XL1-Blue cells at $3000 \mathrm{~g}, 15 \mathrm{~min}$ ) mixed with $10 \mu \mathrm{L} 5 \%$ milk (v/v) in PBST was added to each well and incubated at $37^{\circ} \mathrm{C}$ for $1 \mathrm{~h}$. The resulting plates were rinsed eight times using PBST before subjecting to horseradish peroxidase (HRP) detection. A solution containing the secondary antibody, anti-M13 bacteriophage antibody conjugated with HRP (dilution factor 1 : 5000; Sino Biological, \#11973-MM05T-H), was added into the above plates (150 $\mu \mathrm{L} /$ well) and incubated at $37^{\circ} \mathrm{C}$ for $1 \mathrm{~h}$. Plates were then washed eight times with PBST followed by the addition of $50 \mu \mathrm{L}$ ABTS solution (Roche, \#11684302001) into each well. After $\sim 10$ min incubation at room temperature, the absorbance change at $405 \mathrm{~nm}$ in each well was measured on a microplate reader (Enspire, PerkinElmer).

\section{Competitive ELISA}

Competition between the selected antibodies and hACE2 for binding to the SARS-CoV-2 
372 spike protein RBD was measured. The recombinant $h$ ACE2-ECD was coated in PBS

373 buffer at $2 \mathrm{ng} / \mu \mathrm{L}, 100 \mu \mathrm{L}$ per well at $4{ }^{\circ} \mathrm{C}$ overnight, washed with PBS once, then blocked with 3\% BSA in PBS. Biotinylated S-RBD ( $h$ Fc tag removed by thrombin digestion) at a

375 final concentration of $50 \mathrm{nM}$ was incubated with 2-fold serial diluted S-B8, S-D4, and S376 E6 antibodies (from $1-133 \mathrm{nM}$ ) at $4{ }^{\circ} \mathrm{C}$ for $30 \mathrm{~min}$, in which an IgG4e1 isotype antibody 377 was used as the negative control. The S-RBD and antibody mixture was then added to the hACE2-ECD coated plates and incubated at room temperature for $1 \mathrm{~h}$, followed by 4 washes with PBST. The hACE2-ECD bound S-RBD in the plate was detected using a Streptavidin-HRP conjugated protein.

\section{Affinity determination by Biolayer Interferometry (BLI)}

Binding affinities of S-D4 with SARS-CoV-2 S-RBD were performed by BLI on an Octet RED96 (Molecular Devices LLC, San Jose, CA, USA) using AR2G biosensors. The SARS-CoV-2 S-RBD fused $h$ Fc was first digested by thrombin to remove the Fc tag. The resulting S-RBD diluted in a PBS solution containing $0.02 \%$ Tween-20 and $0.05 \%$ BSA (PBST-B) $(10 \mu \mathrm{g} / \mathrm{mL})$ was loaded to the AR2G biosensor by amine coupling. The AR2GS-RBD sensors were dipped into a PBST-B for $60 \mathrm{sec}$ to establish a baseline, and then incubated with 2-fold serial diluted antibody solutions to record the progressive curves of association. Finally, sensors were incubated in a PBST-B buffer to record the progressive curves of dissociation. For S-B8 and S-E6 detections, S-RBD was first biotinylated before loading to a streptavidin (SA) sensor, the remaining procedure was same to that of S-D4. Sensor regeneration was performed by dipping the used sensors into a $\mathrm{pH} 3.4$ citrate acid buffer, and equilibrated in a PBST-B buffer. Results were analyzed by ForteBio Data 
Analysis software.

\section{Interaction of antibodies with cell surface expressed spike by FACS}

In a flow-cytometry binding experiment, the spike protein of either full-length SARS-CoV-

2 or SARS, which was conjugated with P2A-EGFP, was transiently transfected into a

FACS buffer (PBS, $0.05 \%$ BSA and 2 mM EDTA). The spike protein expressing cells

$4^{\circ} \mathrm{C}$ for $15 \mathrm{~min}$, the cells were washed twice and re-suspended in a FACS buffer, and spikes. Mean fluorescence intensities of Alexa555 in eGFP-positive cells were recorded and analyzed to evaluate antibody binding.

\section{Size-exclusion-high-performance liquid chromatography (SEC-HPLC)}

410 Twenty $\mu \mathrm{L}$ of $0.5 \mu \mathrm{g} / \mu \mathrm{L}$ purified S-RBD antibodies were applied to an Agilent Bio SEC-5,

411 500A HPLC system. The mobile phase used PBS buffer ( $\mathrm{pH} 7.2$ ) running at a flow rate of

$4120.35 \mathrm{~mL} / \mathrm{min}$. Absorbance was analyzed and integrated by retention time and area under

413 the curve (AUC) to determine the percentage of aggregation, monomer and degradants 414 compositions. 


\section{Cell-cell fusion assay}

The cell-cell fusion assay was established according to a previous report (40) with minor modifications. Briefly, hACE2 positive Vero cells (cells with endogenous hACE2 were sorted by FACS) were used as target cells. HEK293F cells that are transiently transfected with either SARS-CoV-2 spike-P2A-EGFP or SARS spike-P2A-EGFP were set as effector cells. The target Vero cells were first seeded into 24 -well plates at a density of $1 \times 10^{5} /$ well and cultivated at $37{ }^{\circ} \mathrm{C}$ for $4 \mathrm{~h}$, followed by addition of effector cells, HEK293F/SARS spike-EGFP or HEK293F/SARS-CoV-2 spike-EGFP, at a ratio of 2:1, respectively. The co-cultures of cells were cultivated in a DMEM medium with $10 \%$ FBS, and treated with or without anti-SARS-CoV-2 spike antibodies at indicated concentrations. The recombinant SARS-CoV-2 S-RBD was used as a positive control. After cultivating at $37^{\circ} \mathrm{C}$ for $6 \mathrm{~h}$, the rates of cell-cell fusion were evaluated using a fluorescence microscope (EVOS M5000, Life Technologies). Five fields for microscopic analysis were randomly selected in each treated group, the numbers of fused and unfused EGFP positive cells were counted.

\section{Preparation of pseudovirus}

HEK293T cells were co-transfected with both NL4-3 mCherry Luciferase plasmid (addgene \#44965) and pcDNA3.1 SARS-CoV-2 spike $\Delta 19$ plasmid (encoding SARS-CoV2 spike protein, with 19 AA truncated in C terminal) using Lipofectamine 3000 (Invitrogen, L3000-015) following the manufacturer's instruction. Pseudotyped particles were readily released into the supernatant. The supernatants containing SARS-CoV-2 pseudovirus were harvested at $48 \mathrm{~h}$ post-transfection, filtered $(0.45 \mu \mathrm{m}$ pore size, Sartorius, $16533-$ 
$437 \mathrm{~K}$ ), and mixed with the Lenti-X Concentrator (Takara, 631231) overnight at $4{ }^{\circ} \mathrm{C}$. The mixture was then centrifuged at $1500 \mathrm{~g}$ for $45 \mathrm{~min}$ at $4^{\circ} \mathrm{C}$. The cell pellets were collected and re-suspended in a DMEM medium and stored at $-80^{\circ} \mathrm{C}$ until use.

\section{Pseudovirus-based neutralization assay}

441 To detect the neutralization ability of selected antibodies against infection of coronavirus 442 pseudovirus (PSV), HEK293T/hACE2 cells were first seeded into 96-well white bottom with an equal volume of different concentrations of selected antibodies (dilution factor: $37{ }^{\circ} \mathrm{C}$ for $30 \mathrm{~min}$. DMEM with or without PSV in the absence of antibodies were set as controls. After incubation, the PSV mixture was transferred to the culture plates containing HEK293T/hACE2 cells. The DMEM media containing PSV and antibodies were replaced with fresh media after $16 \mathrm{~h}$ treatment, cells were incubated for an additional $48 \mathrm{~h}$. PSV infection efficacy was evaluated by luciferase activity using Bright-Lumi ${ }^{\text {TM }}$ Firefly substrate was added to each well, and the relative luminescence unit (RLU) values were measured on an Envision plate reader (PerkinElmer, Ensight).

\section{Authentic SARS-CoV-2 virus neutralization assay}

455 The study was performed in the CL3 Facility of the University of Oxford operating under 456 license from the HSE, on the basis of an agreed Code of Practice, Risk Assessments 457 (under ACDP) and Standard Operating Procedures. A detailed protocol with supporting data will be prepared shortly (Harding, A, Gilbert-Jaramillo, J, et al., 2020). In brief, this 
rapid, high-throughput assay determines the concentration of antibody that produces a $50 \%$ reduction in infectious focus-forming units of authentic SARS-CoV-2 in Vero cells, as follows. Quadruplicate, $0.5 \log _{10}$ serial dilutions of antibody (11 steps from $100 \mathrm{nM}$ to 1 pM) were pre-incubated with a fixed dose of SARS-CoV-2 (Victoria 01/2020 isolate) before incubation with Vero cells. A 1.5\% carboxymethyl cellulose-containing overlay was used to prevent satellite focus formation. Twenty hours post-infection, the monolayers were fixed with $4 \%$ paraformaldehyde, permeabilized with $2 \%$ Triton X-100 and stained for $\mathrm{N}$ antigen using mAb EY 2A (41). After development with a peroxidase-conjugated antibody and True Blue peroxidase substrate, infectious foci were enumerated by ELISPOT reader. Data were analyzed using four-parameter logistic regression (Hill equation) in GraphPad Prism 8.3.

\section{Autoreactivity assay}

The autoreactivity assay was performed using a HEp-2 anti-nuclear antibodies (ANA) kit (Medical \& Biological Laboratories Co., Ltd, \#4220-12CN) according to the manufacturer's instructions. Briefly, $35 \mu \mathrm{L}$ of $0.1 \mathrm{mg} / \mathrm{mL}$ antibodies were loaded to the wells in a slide pre-seeded with fixed and permeabilized HEp-2 cells and incubated for 20 min at room temperature. Positive serum from autoimmune patients and negative serum from healthy donors provided by the kit were used as controls. After washing twice ( 5 min each), the FITC-conjugated secondary anti-human antibody was incubated with the cells for $20 \mathrm{~min}$ at room temperature. The slide was then washed and mounted with a coverslip before observation on a fluorescent microscope (ZEISS, Axio Observer A1) with a 20x objective. 


\section{Protein production and structure determination}

482 The coding sequence for receptor binding domain (RBD; residues 319-541) of the SARSCoV-2 spike (S) protein was synthesized and cloned into a customized pFastBac vector (42), which was designed to fuse an N-terminal gp67 signal peptide and C-terminal His6generated from the sequencing-confirmed pFastBac construct using the Bac-to-Bac system (Life Technologies). Baculovirus was generated by transfecting purified bacmid DNA into Sf9 cells using FuGENE HD (Promega), and subsequently used to infect suspension cultures of High Five cells (Life Technologies) at a multiplicity of infection (MOI) $72 \mathrm{~h}$ for protein expression. RBD protein that was secreted into the supernatant, harvested, and then concentrated with a $10 \mathrm{kDa}$ MW cutoff Centramate cassette (Pall Corporation). The RBD protein was purified by affinity chromatography using Ni-NTA resin (QIAGEN), followed by size exclusion chromatography on a HiLoad Superdex 200 pg

$\mathrm{NaCl}$ using the same protocol as previously described (43). Fabs were expressed in ExpiCHO cells and purified using CaptureSelect $\mathrm{CH} 1-\mathrm{XL}$ resin (ThermoFisher) and mixing the two components in an equimolar ratio and incubating overnight at $4{ }^{\circ} \mathrm{C}$ before setting-up crystal trials. The Fab/RBD complexes were screened for crystallization using

501384 conditions of the JCSG Core Suite (QIAGEN) on our robotic CrystalMation system

502 (Rigaku) at The Scripps Research Institute. Crystals appeared in the first week, were 
503 harvested during the second week, and then flash-cooled in liquid nitrogen for X-ray

504 diffraction experiments. Diffraction data were collected at cryogenic temperature (100 K)

505 at beamline 23-ID-B of the Advanced Photon Source (APS) at Argonne National

506 Laboratory with a beam wavelength of $1.033 \AA$ and processed with HKL2000 (44).

507 Diffraction data were collected from crystals grown in conditions: $20 \%$ PEG 3350, $0.2 \mathrm{M}$

508 sodium sulfate, pH 6.6 for S-B8/RBD complex; 20\% isopropanol, 20\% PEG 4000, $0.1 \mathrm{M}$

509 citrate $\mathrm{pH} 5.6$ for S-E6/RBD complex. The X-ray structures were solved by molecular 510 replacement (MR) using PHASER (45) with MR models for the RBD and Fab from PDB

511 7JMW (46). Iterative model building and refinement were carried out in COOT (47) and

512 PHENIX (48), respectively. Epitope and paratope residues, as well as their interactions,

513 were identified by using PISA program (49) with buried surface area (BSA $\left.>0 \AA^{2}\right)$ as the 514 criterion.

\section{Data analysis and statistics}

516 The results were expressed as means \pm standard deviation (SD) unless otherwise

517 indicated. Data analysis was performed by one-way analysis of variance (ANOVA) using

518 Origin Pro 2019 statistical software or GraphPad Prism software. Significance was 519 assumed at a $P$ value $<0.05$

\section{ACKNOWLEDGEMENTS}

521 We thank Dr. Lichun Jiang, Dr. Wei Wang and Zhangyue Song from the Biomedical Big

522 Data platform of the Shanghai Institute for Advanced Immunochemical Studies (SIAIS) of

523 ShanghaiTech University for sequencing and data analysis, Pengwei Zhang, Dr. Lishuang

524 Zhang and Juan Kong from the high-throughput screening platform of SIAIS for technical 
525 support in cell sorting and phage panning, Jiakang Chen from the Analytical Chemistry

526 Platform of SIAIS for technical support in SEC-HPLC.

\section{FUNDING}

528 Work at ShanghaiTech University was supported by National Natural Science Foundation

529 of China (Grants number 31500632), the China Evergrande Group (Grants number

530 2020GIRHHMS05), and Shanghai Local Grant (Grants number ZJ2020-ZD-004). JPB

531 Foundation supported the work in the Lerner Lab and The Bill and Melinda Gates

532 Foundation OPP1170236 provided support to the Wilson lab. This research used

533 resources of the Advanced Photon Source, a U.S. Department of Energy (DOE) Office of

534 Science User Facility, operated for the DOE Office of Science by Argonne National

535 Laboratory under Contract No. DE-AC02-06CH11357. Extraordinary facility operations

536 were supported in part by the DOE Office of Science through the National Virtual

537 Biotechnology Laboratory, a consortium of DOE national laboratories focused on the

538 response to COVID-19, with funding provided by the Coronavirus CARES Act.

539

540

541

542

543

544

545

546

\section{AUTHOR CONTRIBUTIONS}

R.A.L., G.Y., H.W., W.J., R.A.D, and I.A.W. conceived the project. M.Q., P.X.M., P.D.T., and X.J.S. contributed to project design and extensive discussions. M.Q., P.X.M., Y.L., L.L.L., C.Y.M., Q.J., P.D.T., F.L.W, Z.A.L., A.S. and Y.Z. performed antibody selection, identification, binding, cell-cell fusion and pseudovirus neutralization work. H.J.L., M.Y., N.C.W., C-C.D.L., X.Y.Z. performed structural work involving protein production, crystallization, structure determination and analysis. W.J., A.H. and J.G-J. performed the authentic virus neutralization experiments. G.Y., M.Q., P.X.M., I.A.W. and R.A.L. analyzed 
547 data and wrote the manuscript. X.X.H., W.J. and R.A.D. provided manuscript edits and

548 suggestions.

549 DATA AND MATERIALS AVAILABILITY

550 Correspondence and requests for materials should be addressed to Richard A. Lerner

551 (rlerner@scripps.edu). X-ray coordinates and structure factors for S-B8 and S-E6 in

552 complex with the SARS-CoV-2 RBD have been deposited in the RCSB Protein Data Bank

553 under accession codes: 7KN3, 7KN4.

554

555

556

557

558

559

560

561

562

563

564

565

566

567

568

569

570

571

572

573 10. Y. Cao et al., Potent neutralizing antibodies against SARS-CoV-2 identified by

1. N. Vabret et al., Immunology of COVID-19: current state of the science. Immunity 52, 910-941 (2020).

2. E. O. Saphire et al., Systematic analysis of monoclonal antibodies against Ebola virus GP defines features that contribute to protection. Cell 174, 938-952 (2018).

3. T. F. Rogers et al., Isolation of potent SARS-CoV-2 neutralizing antibodies and protection from disease in a small animal model. Science 369, 956-963 (2020).

4. A. Z. Wec et al., Broad neutralization of SARS-related viruses by human monoclonal antibodies. Science 369, 731-736 (2020).

5. J. Hansen et al., Studies in humanized mice and convalescent humans yield a SARS-CoV-2 antibody cocktail. Science 369, 1010-1014 (2020).

6. S. Ravichandran et al., Antibody signature induced by SARS-CoV-2 spike protein immunogens in rabbits. Sci Transl Med 12, eabc3539 (2020).

7. X. Chi et al., A neutralizing human antibody binds to the N-terminal domain of the Spike protein of SARS-CoV-2. Science 369, 650-655 (2020).

8. P. J. M. Brouwer et al., Potent neutralizing antibodies from COVID-19 patients define multiple targets of vulnerability. Science 369, 643-650 (2020).

9. D. F. Robbiani et al., Convergent antibody responses to SARS-CoV-2 in convalescent individuals. Nature 584, 437-442 (2020).

\section{REFERENCES}


high-throughput single-cell sequencing of convalescent patients' B cells. Cell 182, 73-84 e16 (2020).

11. D. Pinto et al., Cross-neutralization of SARS-CoV-2 by a human monoclonal SARS-CoV antibody. Nature 583, 290-295 (2020).

12. C. Wang et al., A human monoclonal antibody blocking SARS-CoV-2 infection. Nat Commun 11, 2251 (2020).

13. L. Hanke et al., An alpaca nanobody neutralizes SARS-CoV-2 by blocking receptor interaction. Nat Commun 11, 4420 (2020).

14. Y. Wu et al., Identification of human single-domain antibodies against SARS-CoV2. Cell Host Microbe 27, 891-898 e895 (2020).

15. X. Zeng et al., Blocking antibodies against SARS-CoV-2 RBD isolated from a phage display antibody library using a competitive biopanning strategy. bioRxiv, 2020.2004.2019.049643 (2020).

16. F. Bertoglio et al., SARS-CoV-2 neutralizing human recombinant antibodies selected from pre-pandemic healthy donors binding at RBD-ACE2 interface. bioRxiv, 2020.2006.2005.135921 (2020).

17. B. Felding-Habermann et al., Combinatorial antibody libraries from cancer patients yield ligand-mimetic Arg-Gly-Asp-containing immunoglobulins that inhibit breast cancer metastasis. Proc Natl Acad Sci U S A 101, 17210-17215 (2004).

18. R. A. Lerner, Combinatorial antibody libraries: new advances, new immunological insights. Nat Rev Immunol 16, 498-508 (2016).

19. J. Xie, H. Zhang, K. Yea, R. A. Lerner, Autocrine signaling based selection of combinatorial antibodies that transdifferentiate human stem cells. Proc Natl Acad Sci U S A 110, 8099-8104 (2013).

20. Z. Yang et al., A cell-cell interaction format for selection of high-affinity antibodies to membrane proteins. Proc Natl Acad Sci U S A 116, 14971-14978 (2019).

21. T. Zheng et al., Antibody selection using clonal cocultivation of Escherichia coli and eukaryotic cells in miniecosystems. Proc Natl Acad Sci U S A 115, E6145-E6151 (2018).

22. M. Qiang et al., Selection of an ASIC1a-blocking combinatorial antibody that protects cells from ischemic death. Proc Natl Acad Sci U S A 115, E7469-E7477 (2018).

23. C. S. Gao, O. Brummer, S. L. Mao, K. D. Janda, Selection of human metalloantibodies from a combinatorial phage single-chain antibody library. J Am 
609

610

611

612

613

614

615

616

617

618

619

620

621

622

623

624

625

626

627

628

629

630

631

632

633

634

635

636

637

638

639

24. See MATERIALS AND METHODS section.

25. C. W. Tan et al., A SARS-CoV-2 surrogate virus neutralization test based on antibody-mediated blockage of ACE2-spike protein-protein interaction. Nat Biotechnol 38, 1073-1078 (2020).

26. H. Yao et al., Patient-derived mutations impact pathogenicity of SARS-CoV-2. medRxiv, 2020.2004.2014.20060160 (2020).

27. J. Lan et al., Structure of the SARS-CoV-2 spike receptor-binding domain bound to the ACE2 receptor. Nature 581, 215-220 (2020).

28. R. L. Stanfield, I. A. Wilson, Antibody structure. Microbiol Spectr 2, AID-0012-2013 (2014).

29. I. A. Wilson, R. L. Stanfield, Antibody-antigen interactions. Curr Opin Struc Biol 3, 113-118 (1993).

30. J. Ye, N. Ma, T. L. Madden, J. M. Ostell, IgBLAST: an immunoglobulin variable domain sequence analysis tool. Nucleic Acids Res 41, W34-40 (2013).

31. N. C. Wu et al., An alternative binding mode of IGHV3-53 antibodies to the SARSCoV-2 receptor binding domain. Cell Rep 33, 108274 (2020).

32. M. Yuan et al., Structural basis of a shared antibody response to SARS-CoV-2. Science 369, 1119-1123 (2020).

33. C. O. Barnes et al., SARS-CoV-2 neutralizing antibody structures inform therapeutic strategies. Nature, (2020).

34. M. Yuan, H. Liu, N. C. Wu, I. A. Wilson, Recognition of the SARS-CoV-2 receptor binding domain by neutralizing antibodies. Biochem Biophys Res Commun, (2020).

35. R. A. Lerner, Rare antibodies from combinatorial libraries suggests an S.O.S. component of the human immunological repertoire. Mol Biosyst 7, 1004-1012 (2011).

36. C. Kreer et al., Longitudinal isolation of potent near-germline SARS-CoV-2neutralizing antibodies from COVID-19 patients. Cell 182, 843-854 e812 (2020).

37. E. Seydoux et al., Analysis of a SARS-CoV-2-infected individual reveals development of potent neutralizing antibodies with limited somatic mutation. Immunity 53, 98-105 (2020). 
640

641

642

643

644

645

646

647

648

649

650

651

652

653

654

655

656

657

658

659

660

661

662

663

664

665

666

38. Y. Weisblum et al., Escape from neutralizing antibodies by SARS-CoV-2 spike protein variants. elife 9, e61302 (2020).

39. L. Xu et al., Design and characterization of a human monoclonal antibody that modulates mutant Connexin 26 hemichannels implicated in deafness and skin disorders. Front Mol Neurosci 10, 298 (2017).

40. S. Xia et al., Inhibition of SARS-CoV-2 (previously 2019-nCoV) infection by a highly potent pan-coronavirus fusion inhibitor targeting its spike protein that harbors a high capacity to mediate membrane fusion. Cell Res 30, 343-355 (2020).

41. K.-Y. A. Huang et al., Breadth and function of antibody response to acute SARSCoV-2 infection in humans. bioRxiv, 2020.2008.2028.267526 (2020).

42. D. C. Ekiert et al., A highly conserved neutralizing epitope on group 2 influenza A viruses. Science 333, 843-850 (2011).

43. M. Yuan et al., A highly conserved cryptic epitope in the receptor binding domains of SARS-CoV-2 and SARS-CoV. Science 368, 630-633 (2020).

44. Z. Otwinowski, W. Minor, Processing of X-ray diffraction data collected in oscillation mode. Methods Enzymol 276, 307-326 (1997).

45. A. J. McCoy et al., Phaser crystallographic software. J Appl Crystallogr 40, 658674 (2007).

46. H. Liu et al., Cross-neutralization of a SARS-CoV-2 antibody to a functionally conserved site is mediated by avidity. Immunity (2020), in press.

47. P. Emsley, K. Cowtan, Coot: model-building tools for molecular graphics. Acta Crystallogr D Biol Crystallogr 60, 2126-2132 (2004).

48. P. D. Adams et al., PHENIX: a comprehensive Python-based system for macromolecular structure solution. Acta Crystallogr D Biol Crystallogr 66, 213-221 (2010).

49. E. Krissinel, K. Henrick, Inference of macromolecular assemblies from crystalline state. J Mol Biol 372, 774-797 (2007). 
A.

\begin{tabular}{lll}
\hline Round ofpanning & Input & Output \\
\hline Round 1-pH 2.2 Elution & $1 \times 10^{13}$ & $2 \times 10^{6}$ \\
Round 2-pH 2.2 Elution & $1 \times 10^{13}$ & $2 \times 10^{7}$ \\
Round 3-hACE2-ECD Elution & $3 \times 10^{13}$ & $4 \times 10^{9}$ \\
\hline
\end{tabular}

* Output vs. panning round with antigen S-RBD- $h \mathrm{Fc}$ and negative control $h \mathrm{Fc}$.

B.

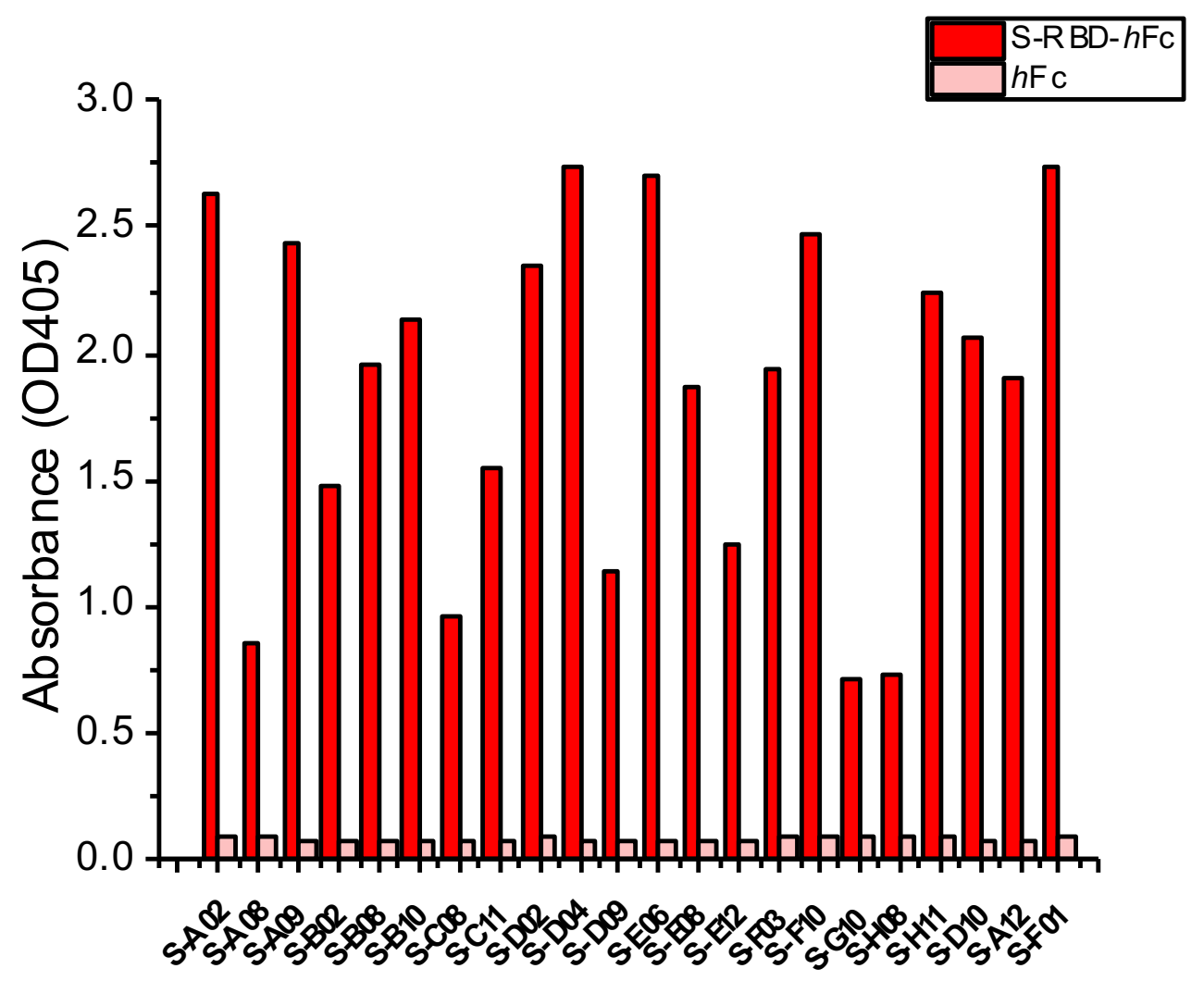


bioRxiv preprint doi: https://doi.org/10.1101/2020 11.06.370676. this version posted November 6, 2020. The copyright holder for this preprint (which was not certified by peer review) is the author/funder, who has granted bioRxiv a license to display the preprint in perpetuity. It is made available under aCC-BY-NC-ND 4.0 International license.

669 Figure 1. Selection of ScFv antibodies targeting spike protein. (A) Output vs. panning

670 round for the antigen S-RBD- $h F c$ during three rounds of screening. (B) Phage ELISA

671 results of 22 unique antibodies with positive readouts (OD405 ratio S-RBD-hFc/hFc $>2$ ). 
A.

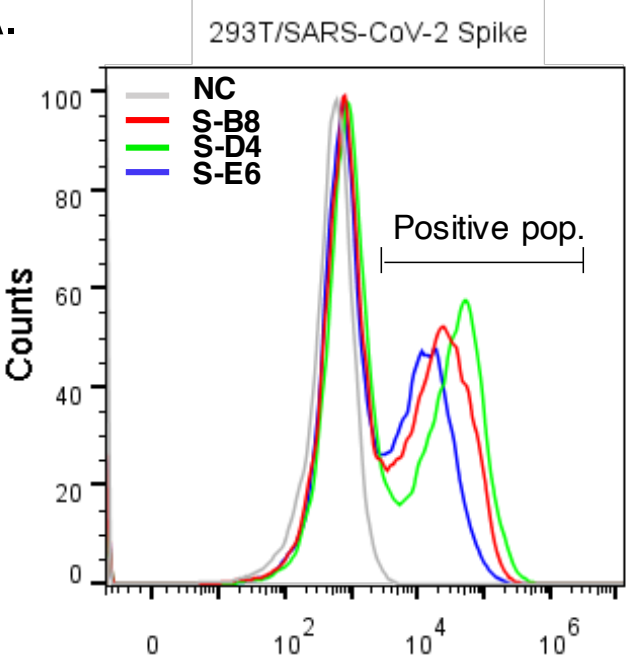

Fluo. Int.

C.

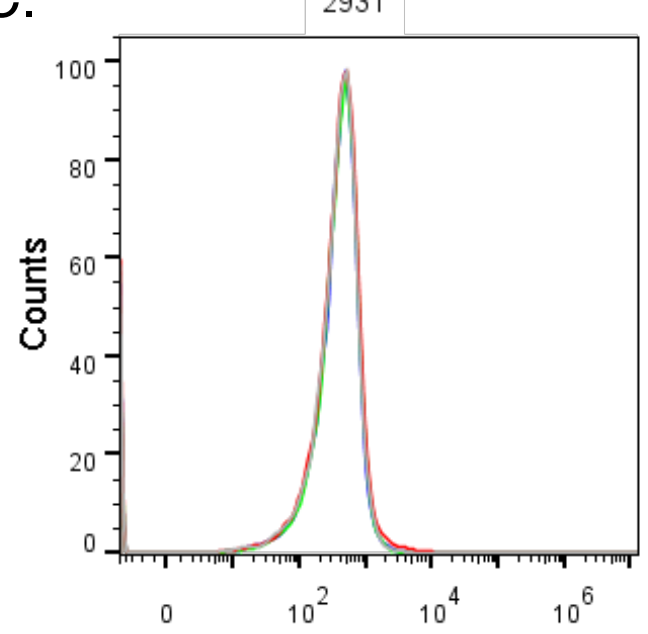

Fluo. Int.

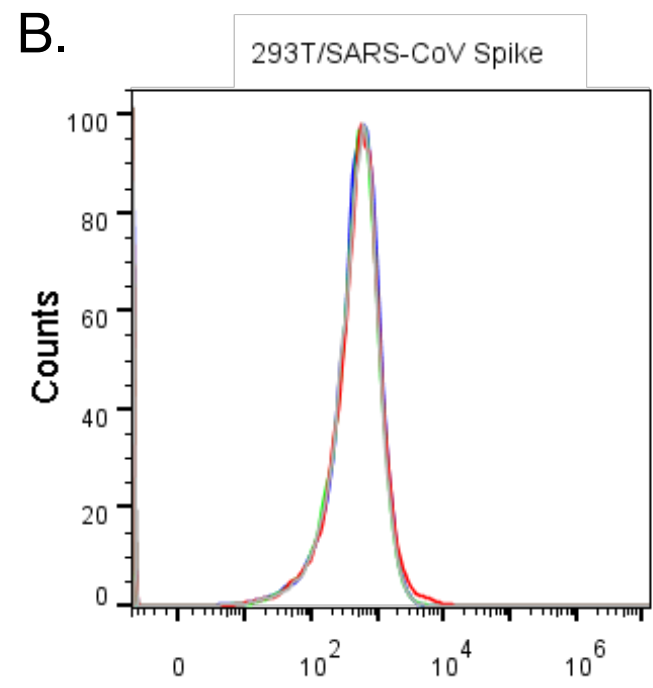

Fluo. Int.

D.

\begin{tabular}{lllll}
\hline Abs & NC & S-B8 & S-D4 & S-E6 \\
\hline MFI & 11505 & 33093 & 42979 & 18215 \\
\hline
\end{tabular}

677 labeled anti-human IgG4 Fc secondary antibody, then analyzed by FACS. Positive

678 binding cells populations were labeled as positive pop. (B) FACS of antibodies binding to 
679 SARS-CoV spike. (C) FACS of antibodies binding to non-transfected HEK293T cells.

680 Cells stained with only secondary antibody were used as negative control (NC). (D) Mean

681 fluorescent intensity (MFI) of antibodies for SARS-CoV-2 spike binding, i.e. positive

682 population area in $\mathbf{A}$. 

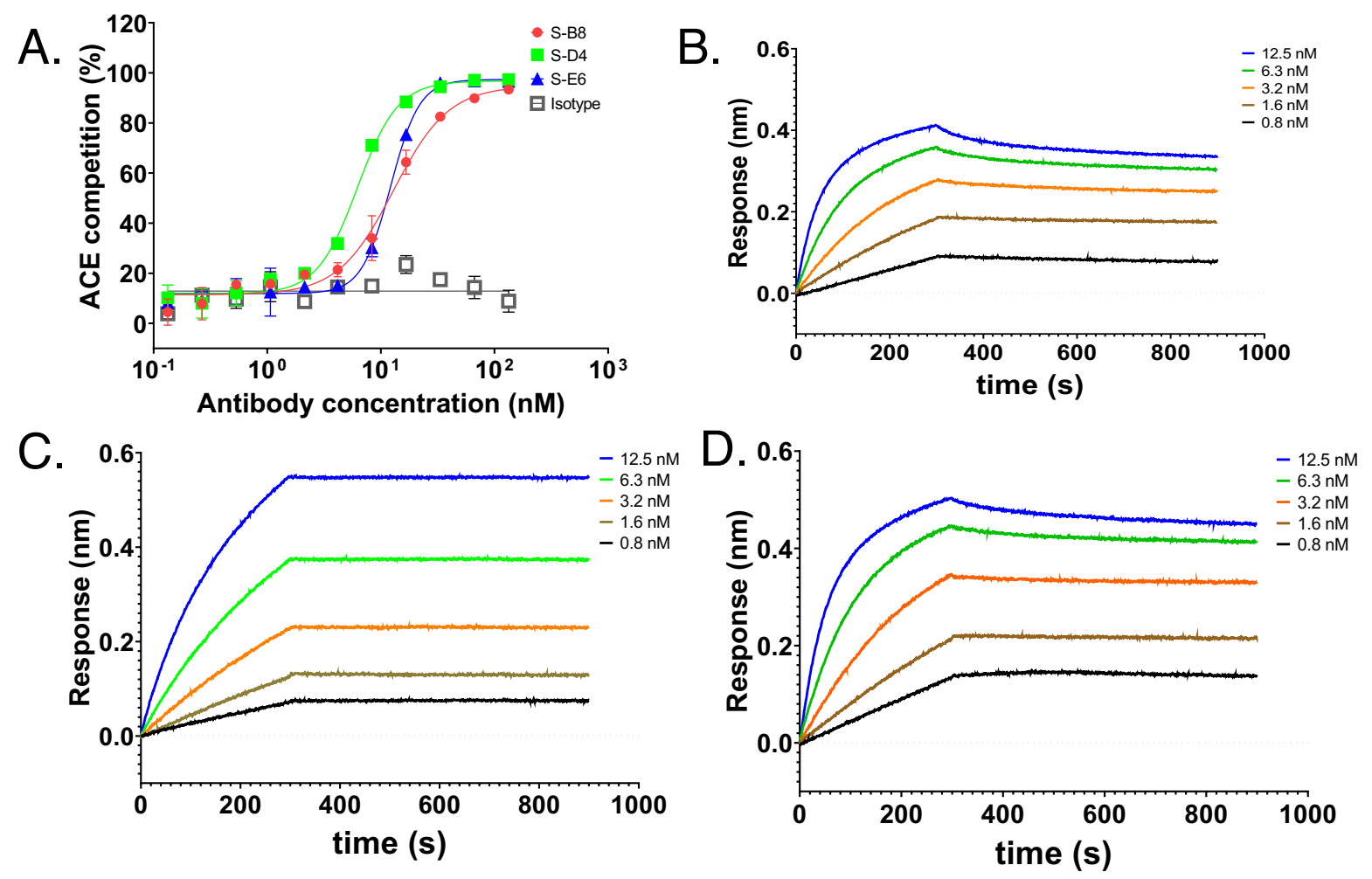

E.

\begin{tabular}{ccccc}
\hline Abs & $\boldsymbol{K}_{\text {on }}(\mathbf{1} / \mathrm{Ms})$ & $\boldsymbol{K}_{\text {off }}(\mathbf{1} / \mathrm{S})$ & $\boldsymbol{K}_{\mathrm{D}}(\mathrm{M})$ & $\mathrm{R}^{2}$ value \\
\hline S-B8 & $1.6 \pm 0.3 \times 10^{6}$ & $2.5 \pm 0.2 \times 10^{-4}$ & $1.7 \pm 0.2 \times 10^{-10}$ & 0.9925 \\
S-D4 & $2.8 \pm 0.1 \times 10^{5}$ & $2.8 \pm 0.5 \times 10^{-6}$ & $1.0 \pm 0.2 \times 10^{-11}$ & 0.9968 \\
S-E6 & $1.2 \pm 0.2 \times 10^{6}$ & $1.3 \pm 0.2 \times 10^{-4}$ & $1.1 \pm 0.2 \times 10^{-10}$ & 0.9992 \\
\hline
\end{tabular}
by biolayer interferometry (BLI). Biotinylated S-RBD was loaded to the SA biosensor for detection of binding kinetics with S-B8 and S-E6, while S-RBD amine coupled to AR2G sensor was utilized for S-D4, with detection on Octet. All curves were fitted by a 1:1 binding model using the Data Analysis software (Forte Bio). (E) The association-rate (kon), 
bioRxiv preprint doi: https://doi.org/10.1101/2020.11.06.370676; this version posted November 6, 2020. The copyright holder for this preprint

(which was not certified by peer review) is the author/funder, who has granted bioRxiv a license to display the preprint in perpetuity. It is made available under aCC-BY-NC-ND 4.0 International license.

691 dissociation-rate $\left(\mathrm{K}_{\mathrm{off}}\right)$ and dissociation constant $\left(\mathrm{K}_{\mathrm{D}}\right)$ of the three competitive antibodies

692 are shown. 
A.

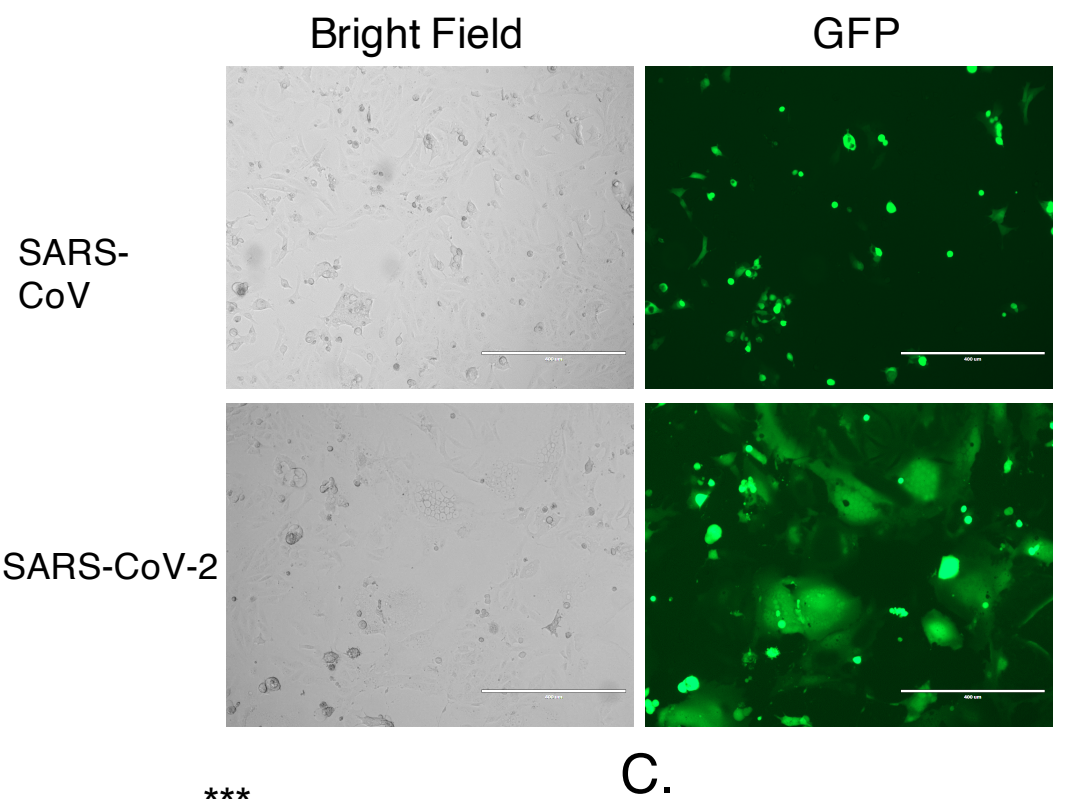

B.
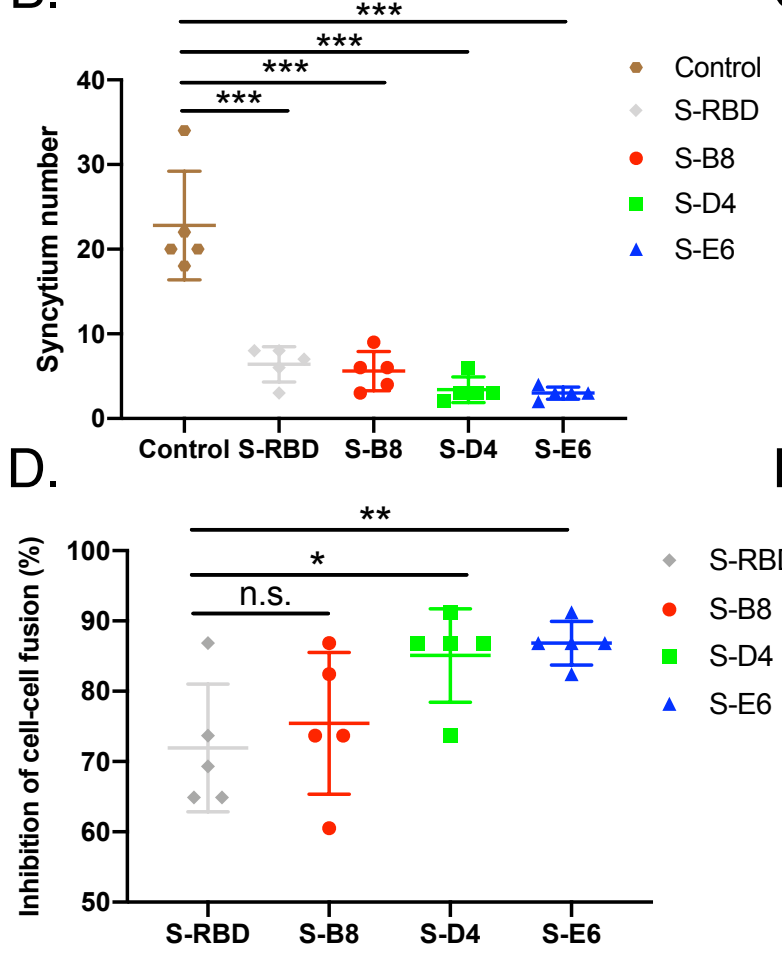

E.

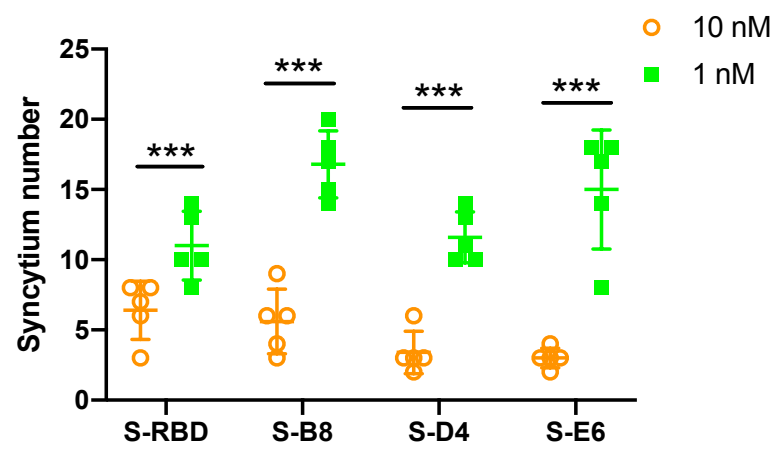

$\mathrm{F}$.

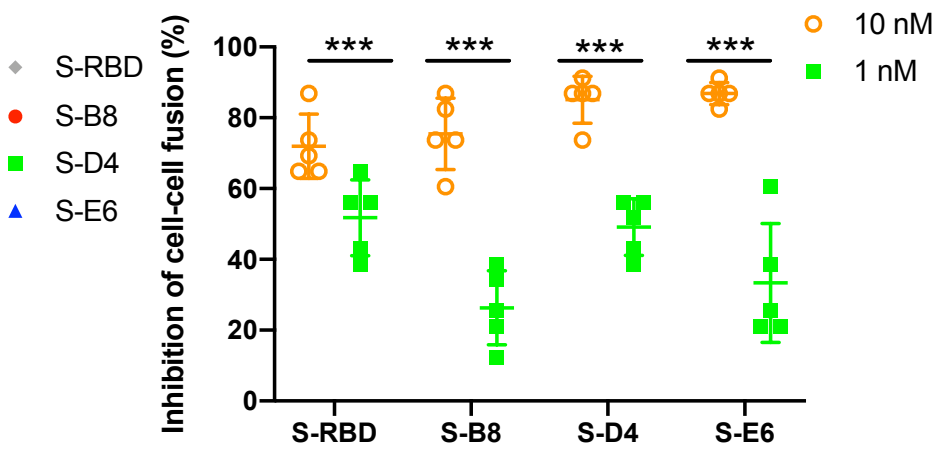

\begin{tabular}{lcccc}
\hline & S-RBD & S-B8 & S-D4 & S-E6 \\
\hline $10 \mathrm{nM}$ & $72 \%$ & $75 \%$ & $85 \%$ & $87 \%$ \\
$1 \mathrm{nM}$ & $50 \%$ & $17 \%$ & $49 \%$ & $33 \%$ \\
\hline
\end{tabular}


694 Figure 4. Inhibition of syncytium formation by the antibodies. (A) Representative 695 images of SARS-CoV-2 and SARS-CoV spike-mediated syncytium formation with hACE2

696 expressing cells 48 hours after co-culture. (B, D) Syncytium number calculation and 697 inhibition rates when treated with $10 \mathrm{nM}$ of $h \mathrm{ACE} 2$ competitive antibodies are shown. S698 RBD was used as the positive control. (C, E) Syncytium number and inhibition rates 699 treated by antibodies and S-RBD at different concentrations are shown. The inhibition 700 rates at $10 \mathrm{nM}$ and $1 \mathrm{nM}$ are summarized in $\mathbf{F}$. Bars $=400 \mu \mathrm{m}$. Error bars indicate $\mathrm{SD},{ }^{*} P$ $701<0.05,{ }^{* *} P<0.01,{ }^{* * *} P<0.001$, determined by Student's T-test. 


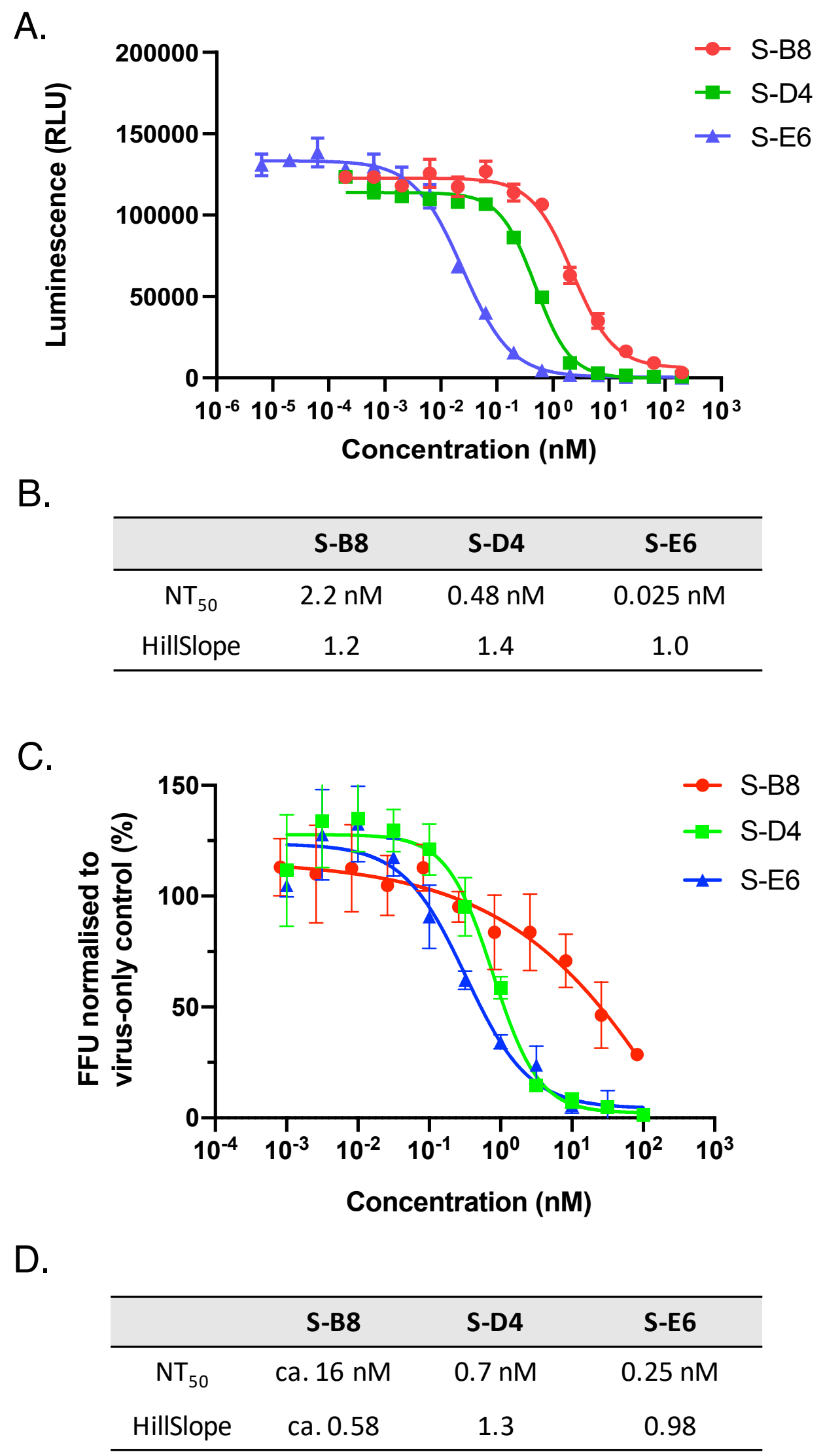


703 Figure 5. Neutralization assay for the hACE2 competitive antibodies. (A)

704 Neutralization ability of the three hACE2 competitive antibodies to SARS-CoV-2

705 pseudovirus was tested and fitted. (C) A microneutralization assay was adopted for

706 testing of the three antibodies. NT 50 and HillSlope for each antibody are summarized in

707 B and C. 
bioRxiv preprint doi: https://doi.org/10.1101/2020.11.06.370676. this version posted November 6, 2020. The copyright holder for this preprint (which was not certified by peer review) is the author/funder, who has granted bioRxiv a license to display the preprint in perpetuity. It is made available under aCC-BY-NC-ND 4.0 International license.

A.

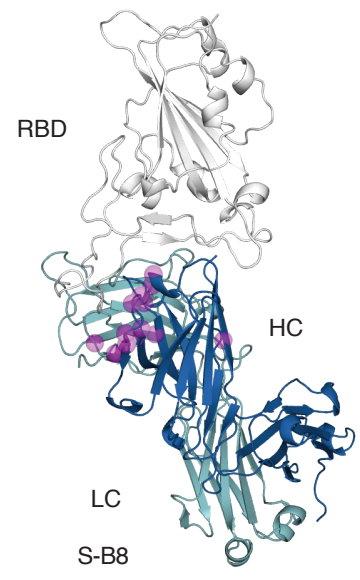

B.

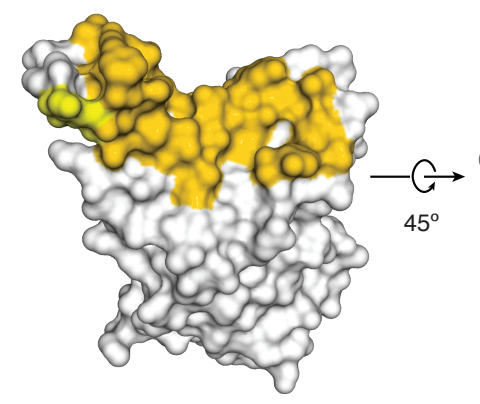

S-B8
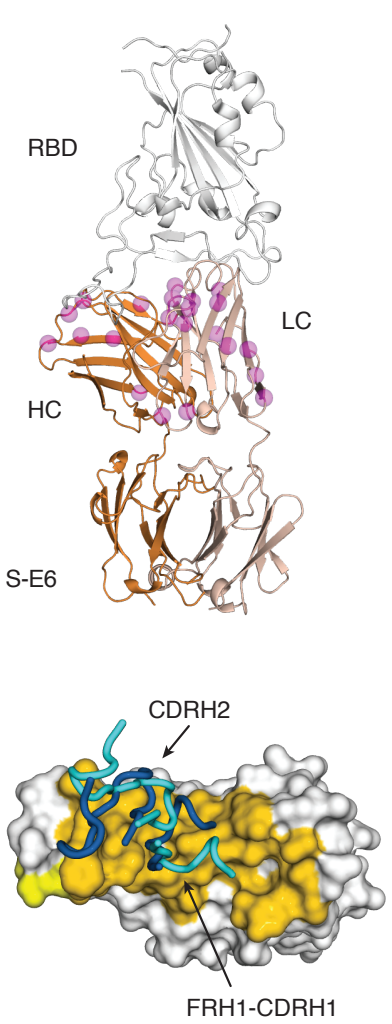

S-B8 : COVA2-39
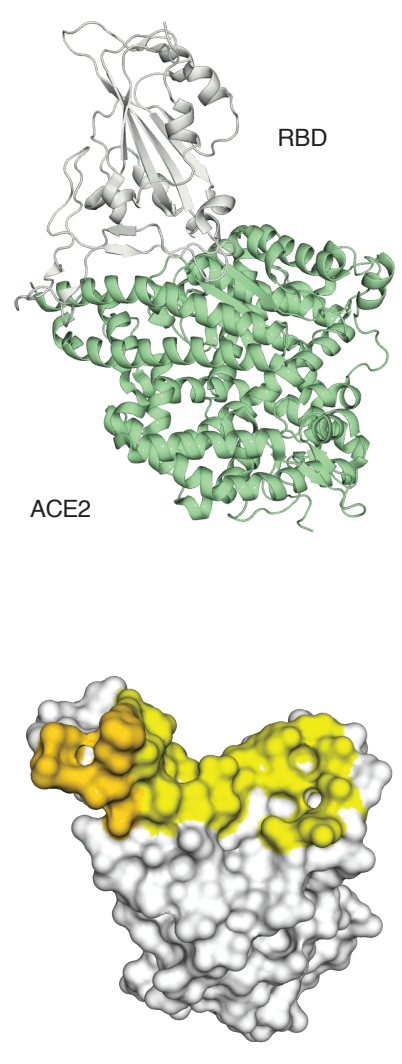

C.

D.

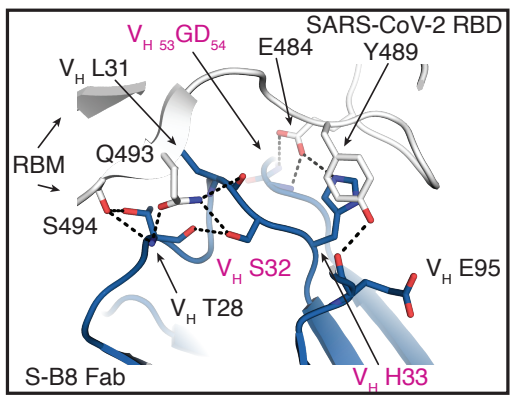

F.

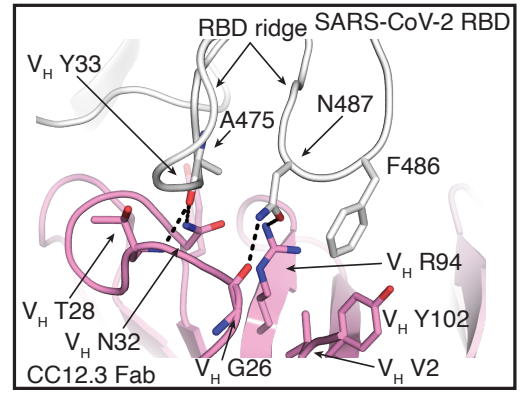

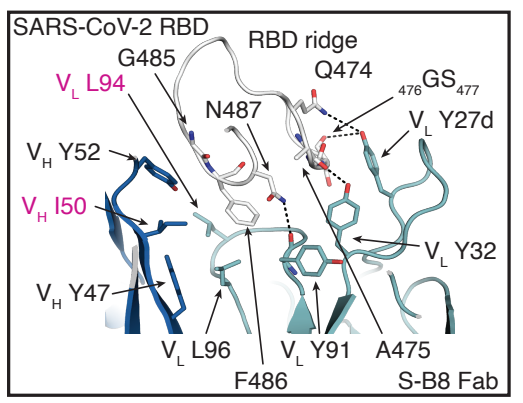

G.

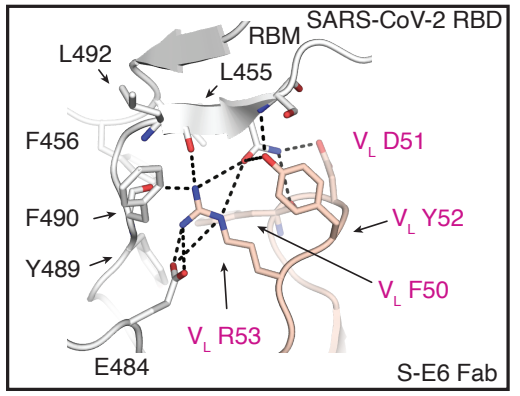

E.

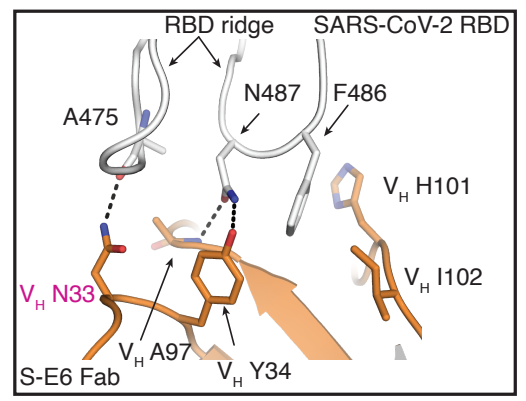

$\mathrm{H}$.

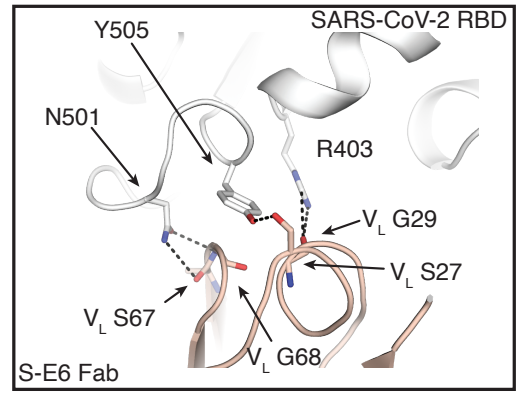


2 S-RBD. Crystal structures are shown in ribbon representation with residues of interest

711 in stick mode. The epitope surface on the RBD involved in interaction with the heavy and

712 light chains of the antibodies are in orange and yellow, respectively. S-RBD is shown in

713 white, S-B8 in blue and light blue for heavy and light chains, and S-E6 heavy and light

714 chains in orange and pink, hACE2 is shown in green. SHM residues are shown as semi-

715 transparent magenta spheres and highlighted with magenta labels in C-H. (A) Structure comparison of S-B8 and S-E6 compared to hACE2 binding to the RBD in the same

717 relative view. (B) Surface representation of S-RBD epitope residue interactions with S-B8 and S-E6. FRH1-CDRH1 and CDRH2 from both S-B8 (blue) and COVA2-39 (cyan, PDB

719 7JMP) are shown for comparison. (C) S-B8 CDRH1 and CDRH2 interaction with RBD.

(D) Interaction between S-B8 and RBD ridge. (E) Interaction between S-E6 and RBD

722 light pink for light chain) in complex with SARS-CoV-2 S-RBD (PDB 6XC7) illustrating the 723 hydrogen bonding between the ${ }_{32} \mathrm{NY}_{33}$ motif and S-RBD. (G) Interaction between S-E6 


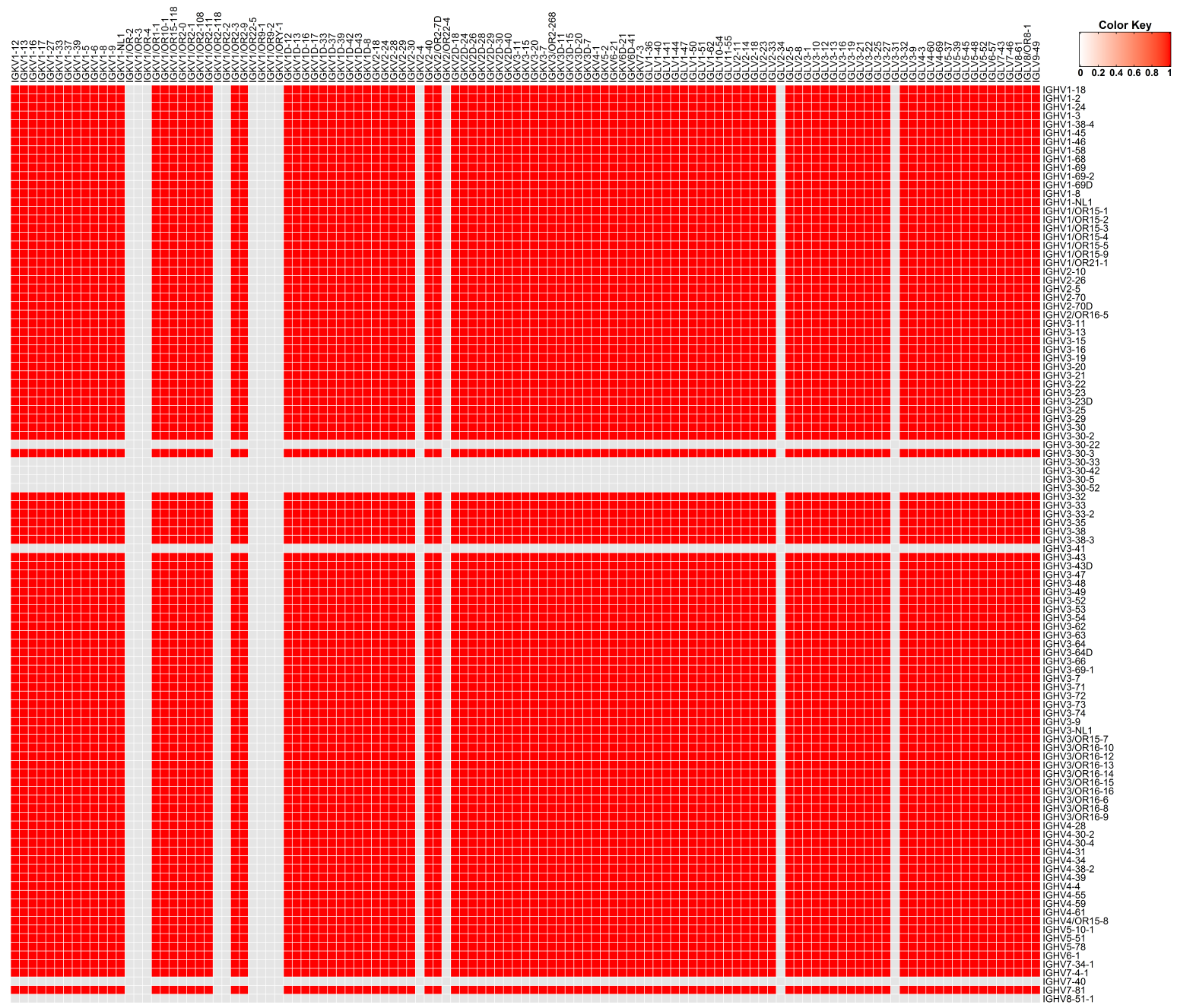

727 Supplementary Figure 1. Germline matrix coverage of the naïve antibody library.

728 The heavy and light chain genes of the naïve antibody library were separately sequenced

729 by next generation sequencing, and the IGHV vs. IGLV and IGKV germline matrix

730 coverage hotmaped (red color) are shown aligned to the full germline distribution derived

731 from IMGT (international ImMunoGeneTics) database (http://www.imgt.org/). 
bioRxiv preprint doi: https://doi.org/10.1101/2020.11.06.370676; this version posted November 6, 2020. The copyright holder for this preprint (which was not certified by peer review) is the author/funder, who has granted bioRxiv a license to display the preprint in perpetuity. It is made available under aCC-BY-NC-ND 4.0 International license.

A.

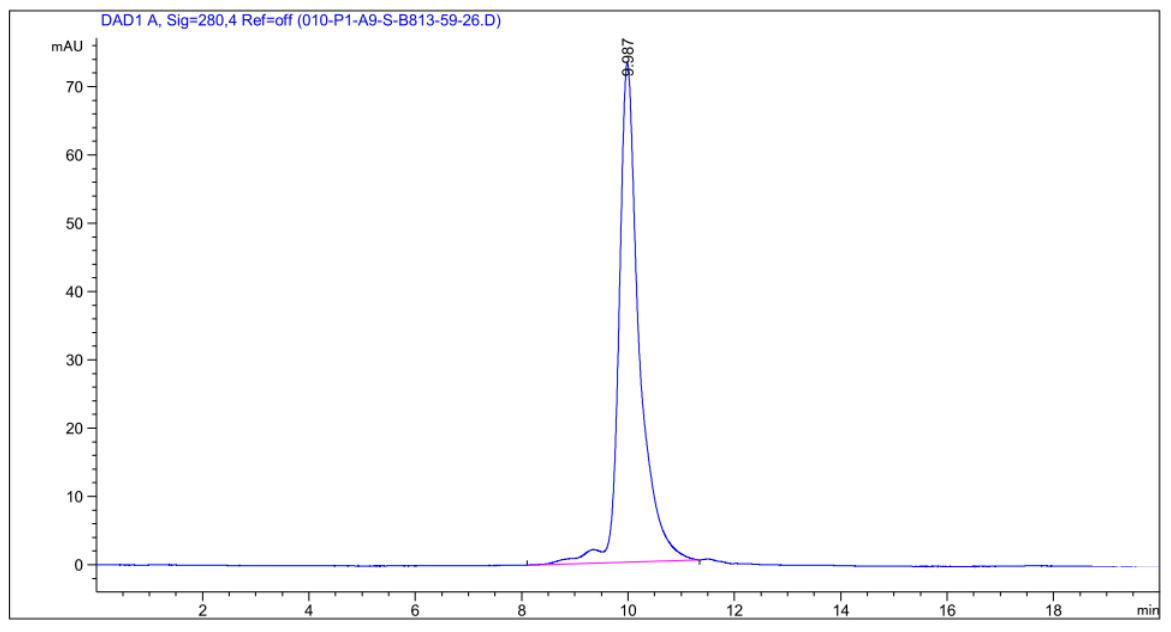

B.

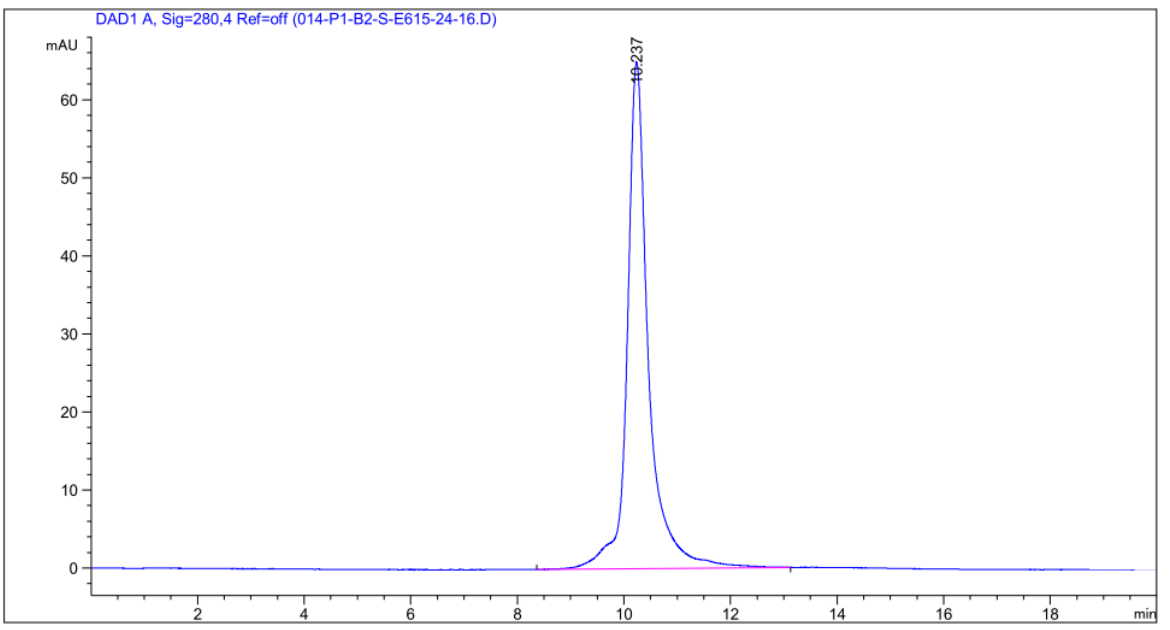

C.

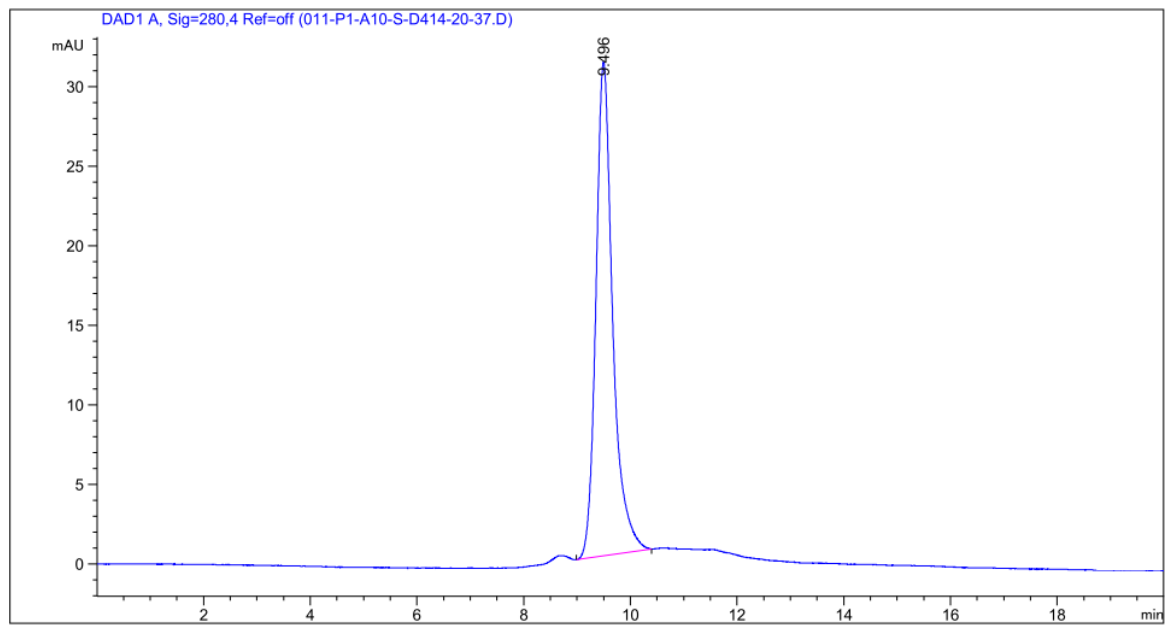


733 Supplementary Figure 2. SEC-HPLC of selected antibodies. SEC-HPLC analysis of

734 S-B8 (A), S-D4 (B) and S-E6 (C) in full length IgG4e1 formats are shown. The antibody

735 used for analysis was at $0.5 \mathrm{mg} / \mathrm{mL}$. 


\section{S-B8 S-D4 S-E6 $\quad \underline{\text { S-B8 }} \quad$ S-D4 $\quad$ S-E6 Non-reduced Reduced}

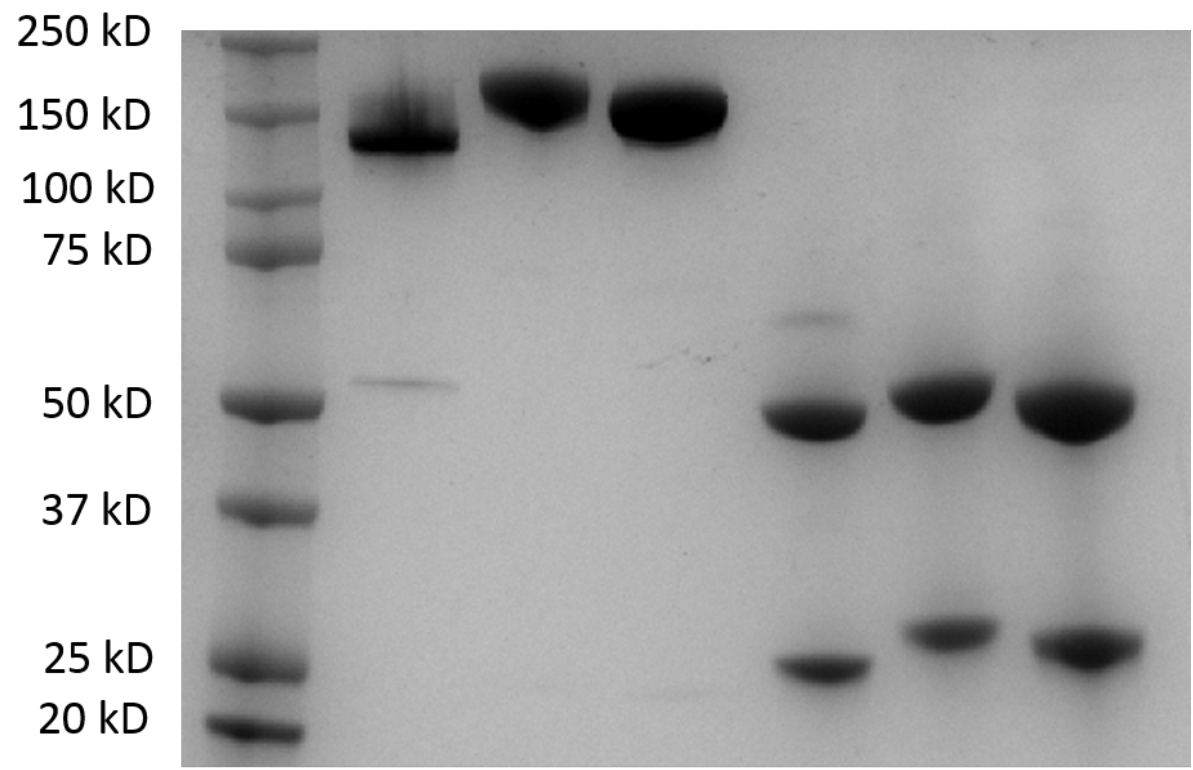

738 Supplementary Figure 3. SDS-PAGE analysis of hACE2 competitive antibodies.

739 Three hACE2 competitive antibodies in IgG4e1 format are analyzed by SDS-PAGE, in 740 both non-reduced and reduced forms. 


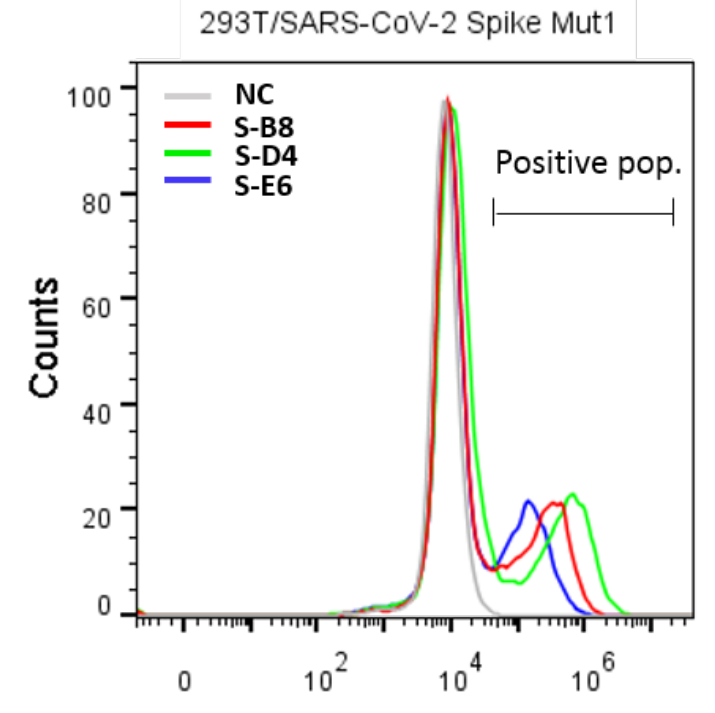

Fluo. Int.

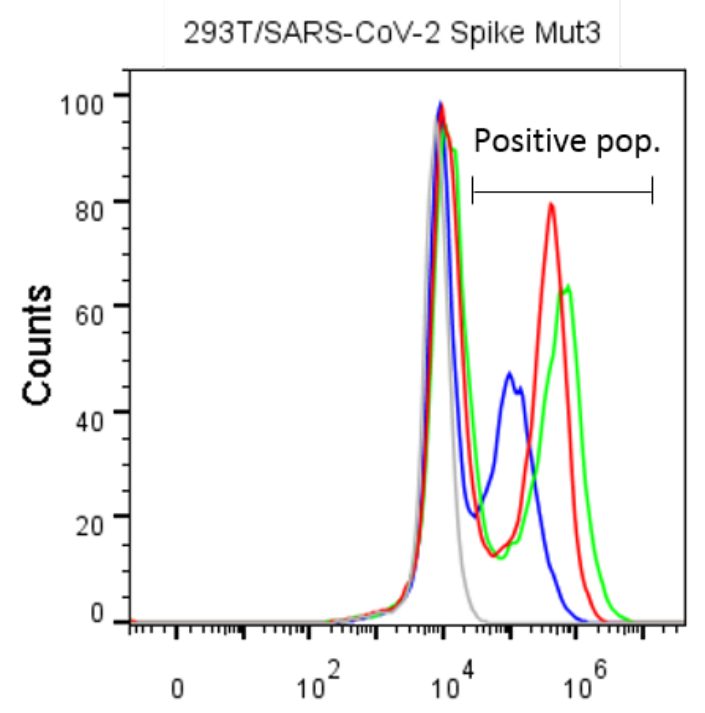

Fluo. Int.

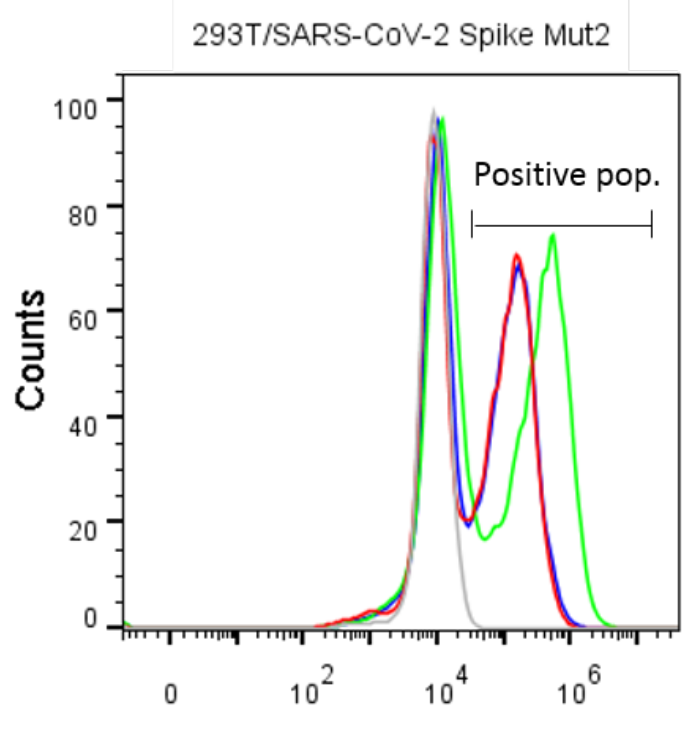

Fluo. Int.

742 Supplementary Figure 4. FACS analysis of antibody binding to cell surface-

743 expressed mutated spike protein. HEK293T cells transfected with expression plasmid

744 encoding the mutated full-length spike of SARS-CoV-2 were incubated with the three hACE2 competitive IgG4 antibodies. The cells were then stained with FITC labeled anti-

746 human IgG Fc secondary antibody and analyzed by FACS. Cells stained with only 
bioRxiv preprint doi: https://doi.org/10.1101/202011.06.370676. this version posted November 6, 2020. The copyright holder for this preprint

(which was not certified by peer review) is the author/funder, who has granted bioRxiv a license to display the preprint in perpetuity. It is made available under aCC-BY-NC-ND 4.0 International license.

747 secondary antibody were set as negative control (NC). Positive binding cells populations

748 were labeled as positive pop. 
1

10 20 30 40 50 60

70 80 90 IGHV3-53*01 EVQLVESGGGLIQPGGSLRL SCAASGFTVSSNYMS WVRQAPGKGLEWVSVIYSGGSTYYADSVKGRFTISRDNSKNTLYLQMNSLRAEDTAVYYCAR IGHV3-53*02 EVQLVETGGGLIQPGGSLRLSCAASGFTVSSNYMSWVRQAPGKGLEWVSVIYSGGSTYYADSVKGRFT ISRDNSKNTLYLQMNSLRAEDTAVYYCAR IGHV3-53*04 EVOLVESGGGLVOPGGSLRLSCAASGFTVSSNYMSWVROAPGKGLEWV SVIYSGGSTYYADSVKGRF T ISRHNSKNT LYLOMNSLRAEDTAVYYCAR

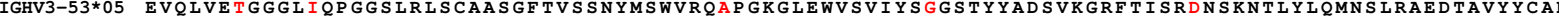

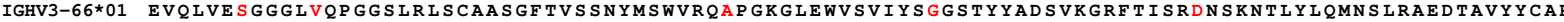
IGHV3 $-66 * 02$ EVQLVESGGGLVQPGGSLRLSCAASGFTVSSNYMSWVRQAPGKGLEWVSVIYSGGSTYYADSVKGRF TISRDNSKNTLYLQMNSLRAEDTAVYYCAR IGHV3-66*03 EVQLVESGGGLIQPGGSLRLSCAASGFTVSSNYMS WVRQAP GKGLEWVSVIYSCGSTYYADSVKGRFT I SRDNSKNTLYLQMNSLRAEDTAVYYCAR are shown in red. 
bioRxiv preprint doi: https://doi.org/10.1101/2020.11.06.370676; this version posted November 6, 2020. The copyright holder for this preprint (which was not certified by peer review) is the author/funder, who has granted bioRxiv a license to display the preprint in perpetuity. It is made available under aCC-BY-NC-ND 4.0 International license.

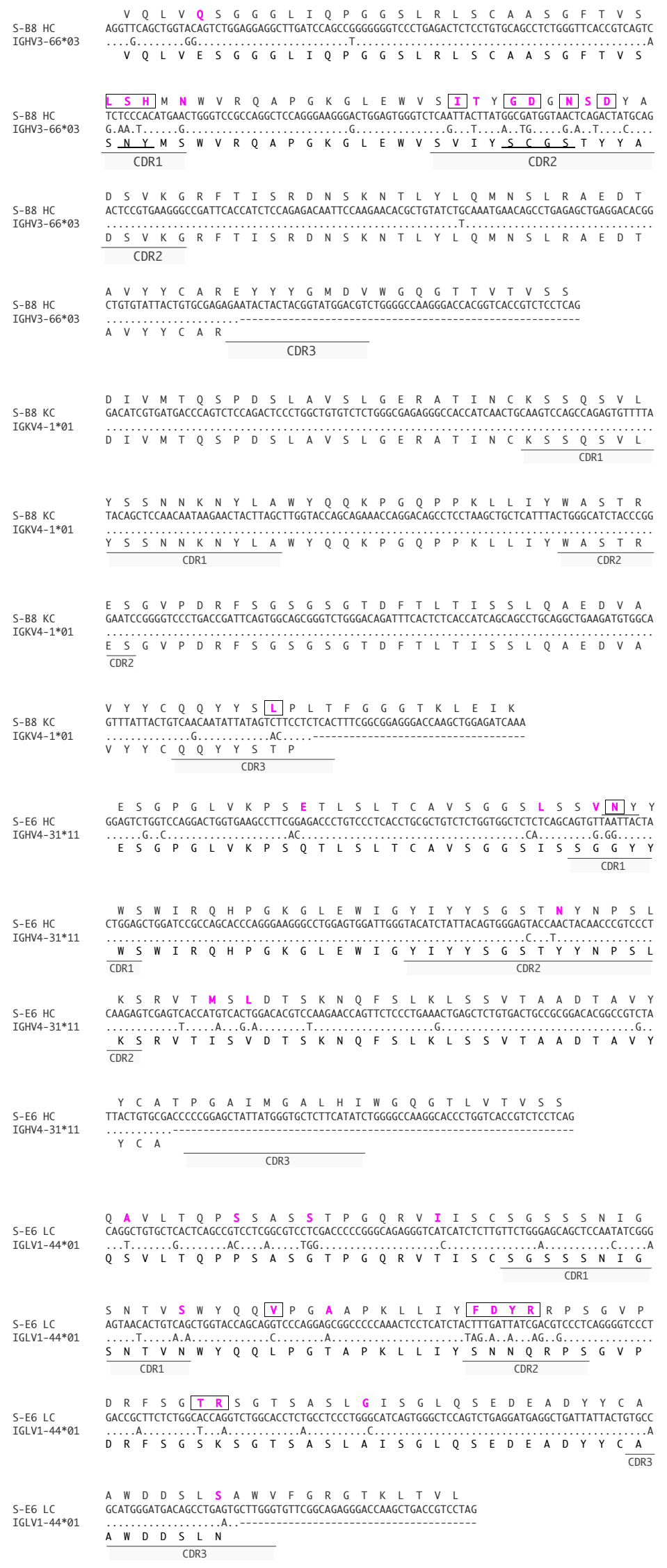


754 Supplementary Figure 6. Germline sequences and somatic hypermutation (SHM)

755 of S-B8 and S-E6. Germline sequences are aligned to heavy and light chain sequences

756 for each antibody. Residues from SHM are colored in purple and residues interacting with

757 SARS-CoV-2 S-RBD are boxed. 


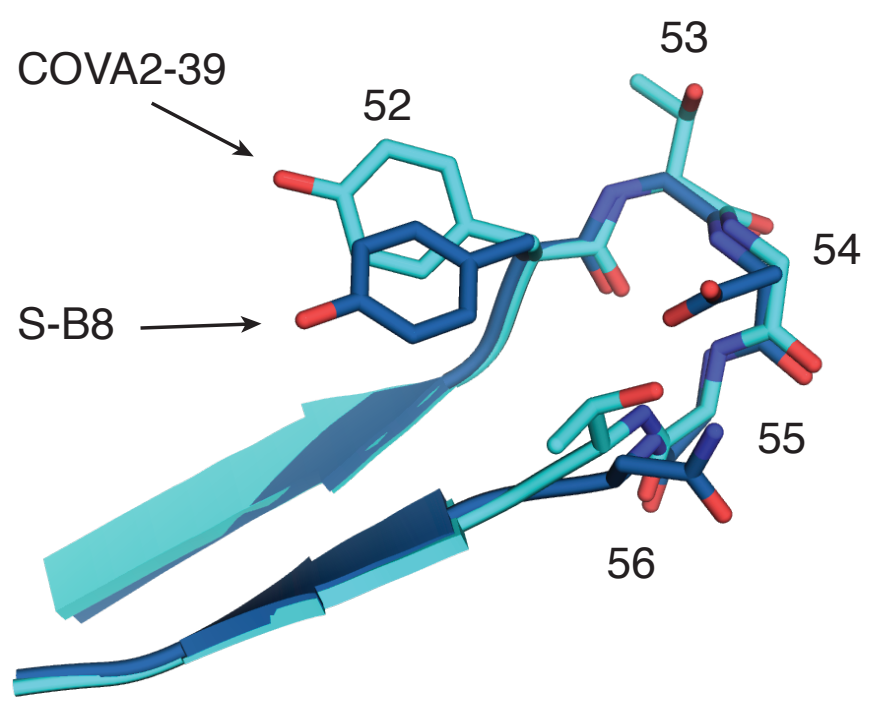

759 Supplementary Figure 7. Structural comparison of CDRH2 between S-B8 and

760 COVA2-39 (PDB 7JMP). Residues in the $\beta$-turn region are shown as sticks with

761 corresponding sequences shown on the right and sequence numbers labeled. 


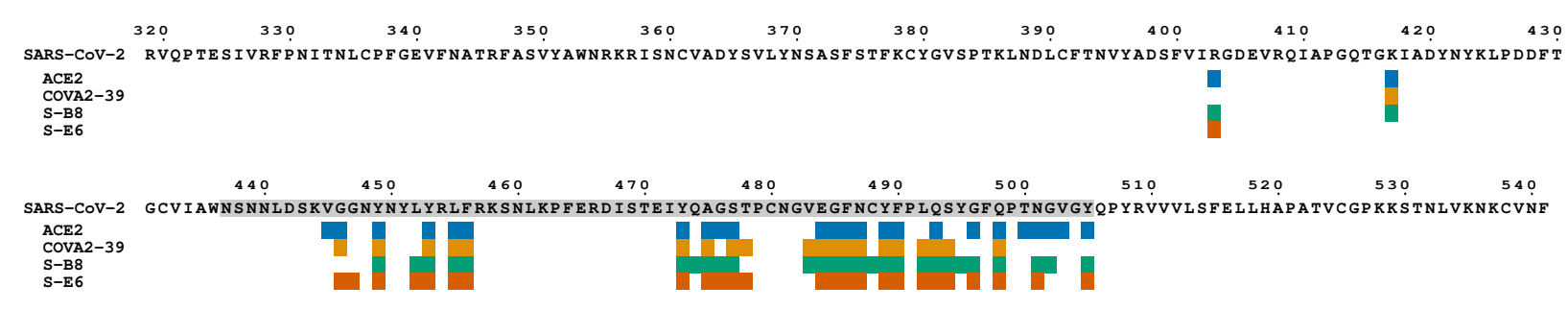

763 Supplementary Figure 8. Fab epitopes and hACE2 binding site. SARS-CoV-2 S-RBD

764 epitopes of S-B8, S-E6 and COVA2-39 (PDB 7JMP) as well as hACE2 binding site on the

765 S-RBD were analyzed with PISA program using buried surface area (BSA) $>0 \AA^{2}$ as the

766 criterion. Each antibody epitope or hACE2 binding site is shown as blocks below the S-

767 RBD sequence under the corresponding residue position. The sequence of the receptor

768 binding motif (RBM) is shaded in grey. 
A.

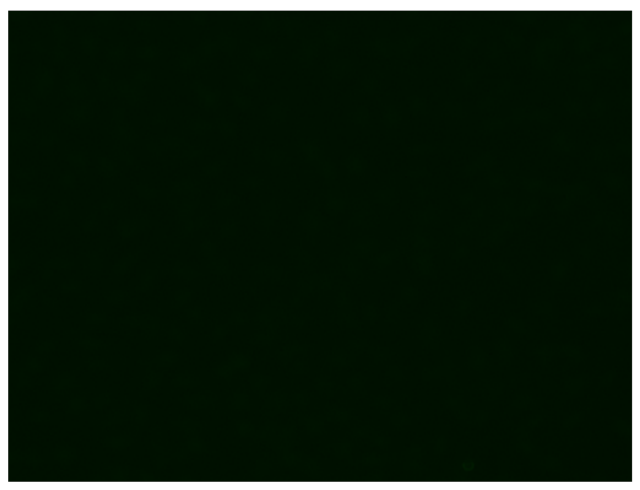

C.

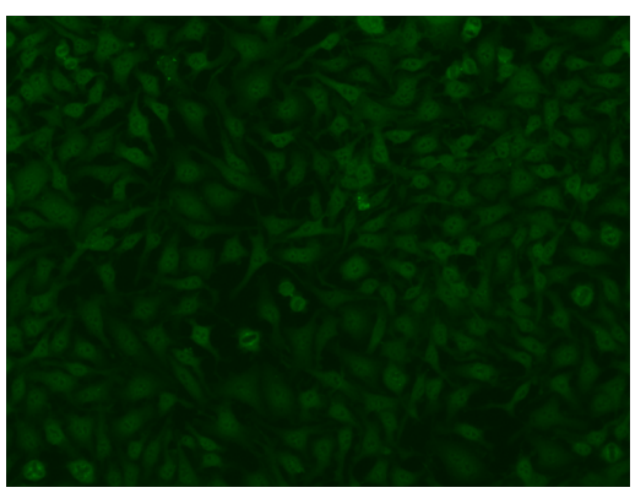

E.

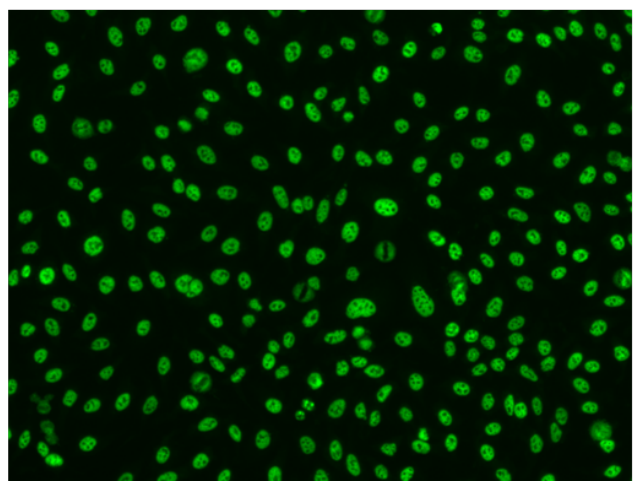

B.

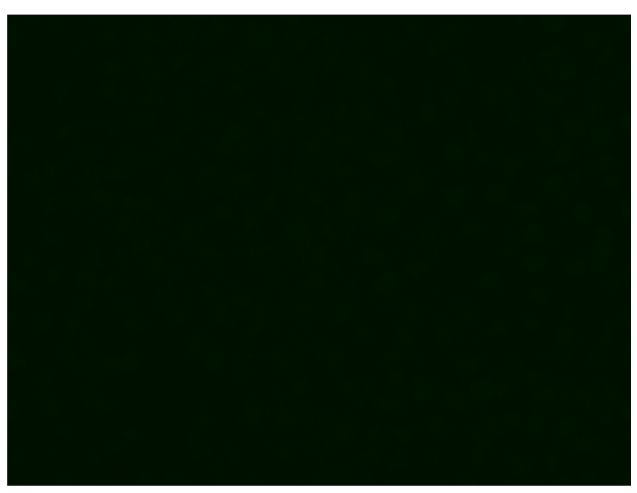

D.

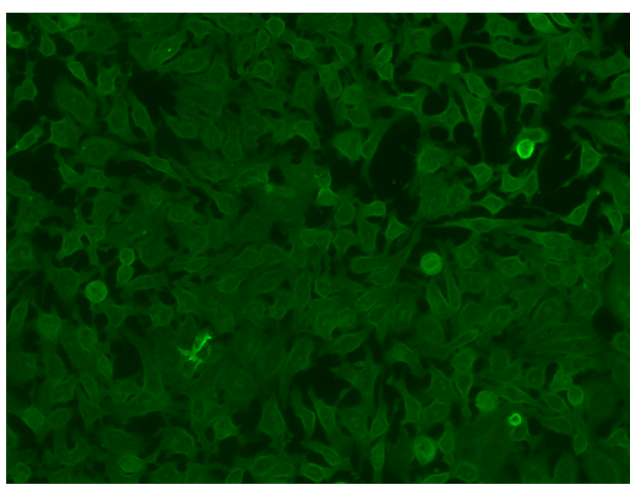

F.

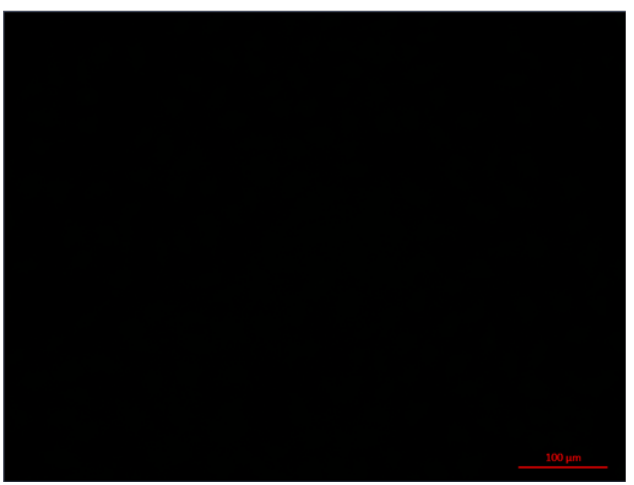

770 Supplementary Figure 9. Autoreactivity detection of selected antibodies.

771 Autoreactivity of S-D4 (A), S-E6 (B), S-B8 (C) and the S-B8 putative germline antibody

772 (D) were tested by using a HEp-2 cell based antinuclear-antibody kit. The S-B8 putative

773 germline antibody was generated by mutating the SHMs of S-B8 back to the germline

774 sequence of IGHV3-66 as shown in Supplementary Figure 6. Positive control (PC) (E) 
bioRxiv preprint doi: https://doi.org/10.1101/2020.11.06.370676 t this version posted November 6, 2020. The copyright holder for this preprint (which was not certified by peer review) is the author/funder, who has granted bioRxiv a license to display the preprint in perpetuity. It is made available under aCC-BY-NC-ND 4.0 International license.

775 and negative control (NC) (F) are from serum of patients with or without autoimmune

776 disease, which is included in the kit. The green color indicates positive binding of the

777 tested antibodies to HEp-2 cells. Bar=100 $\mu \mathrm{m}$. 


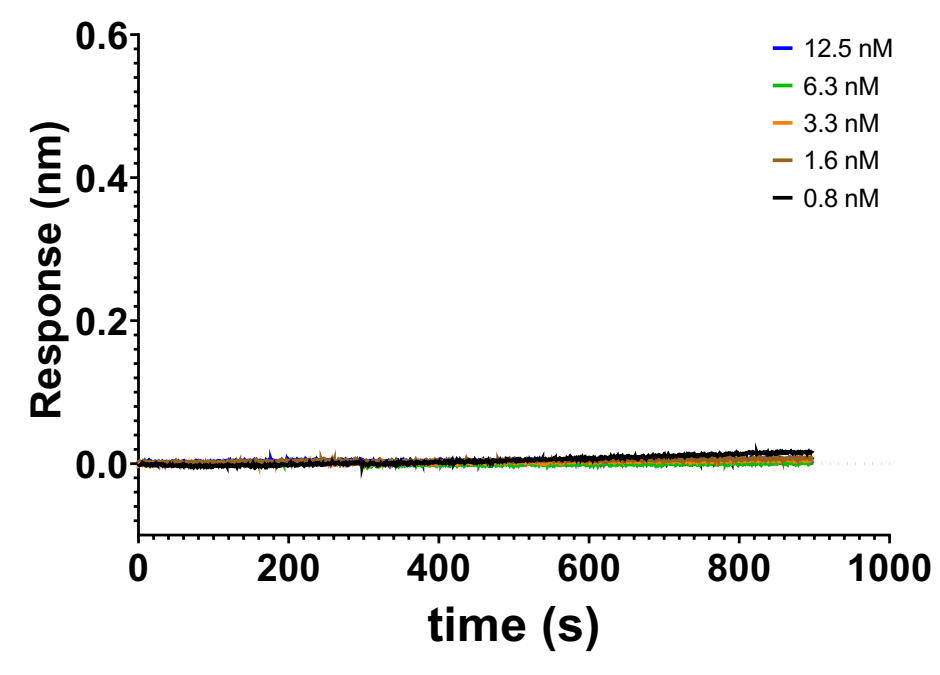

779 Supplementary Figure 10. Binding kinetics of S-B8 putative germline antibody to

780 the spike protein. Binding kinetics were measured by biolayer interferometry (BLI).

781 Biotinylated S-RBD was loaded to the SA biosensor for detection of binding kinetics with

782 the S-B8 putative germline antibody. 
A.

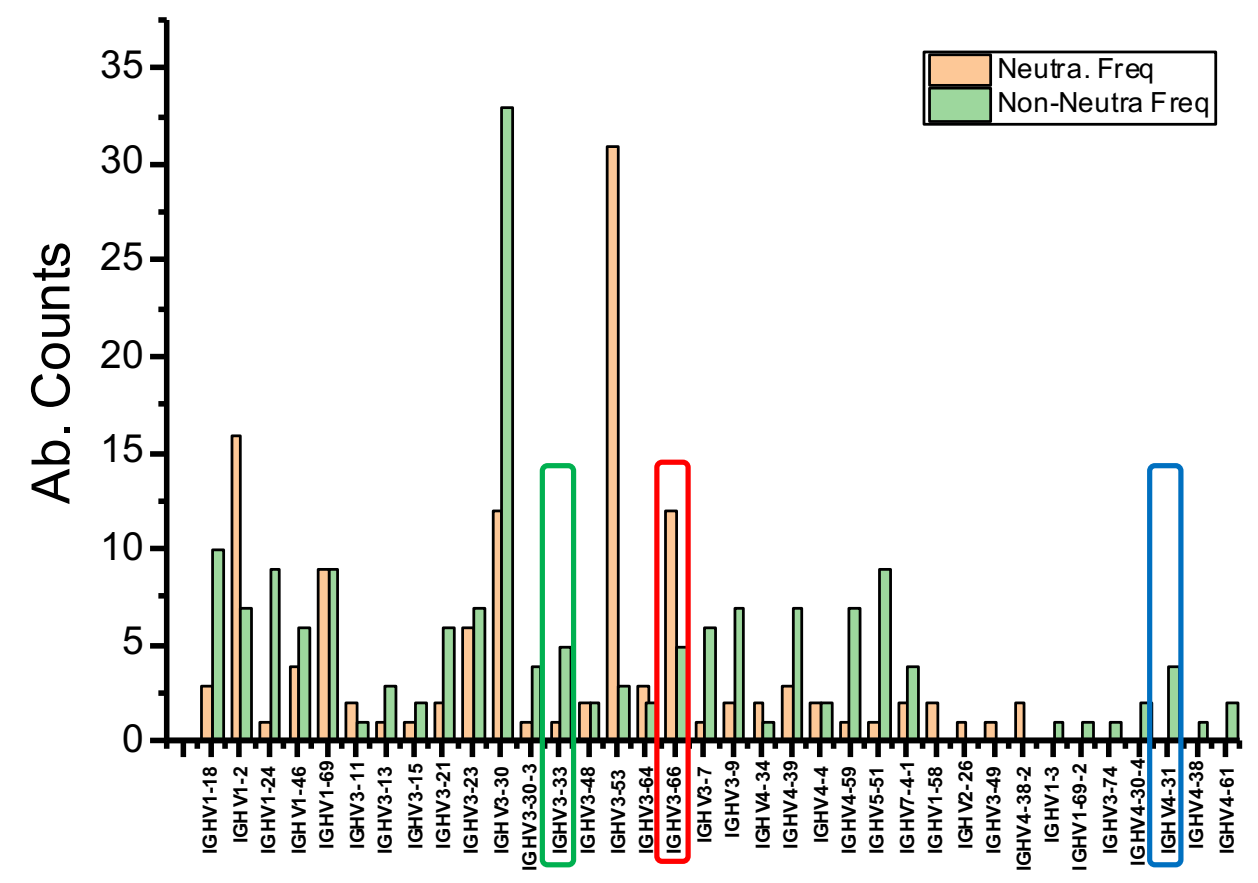

B.

\begin{tabular}{|l|l|}
\hline S-B8 & VH germline \\
\hline S-D4 & IGHV3-66*03 \\
\hline S-E6 & IGHV3-33*01 \\
\hline
\end{tabular}

Supplementary Figure 11. IGHV germline distribution of SARS-CoV-2 spiketargeting antibodies. (A) IGHV distribution of about 300 SARS-CoV-2 binding antibodies reported in the public database

787 (http://opig.stats.ox.ac.uk/webapps/covabdab/\#collapseOne) were analyzed as of June $78820^{\text {th }}, 2020$. The numbers of neutralizing and non-neutralizing antibodies of certain 789 germlines were also calculated and shown. (B) The IGHV of three competitive antibodies 790 are indicated and shown in different colors in the Table and in $\mathbf{A}$. 


\section{Supplementary Table 1. Crystallographic data collection and refinement statistics}

\begin{tabular}{|c|c|c|}
\hline & S-B8 + RBD & S-E6 + RBD \\
\hline \multicolumn{3}{|l|}{ Data collection } \\
\hline Beamline & APS 23ID-B & APS 23ID-B \\
\hline Wavelength $(\AA)$ & 1.03317 & 1.03373 \\
\hline Space group & $R 131$ & $C 121$ \\
\hline \multicolumn{3}{|l|}{ Unit cell parameters } \\
\hline$a, b, c(\AA)$ & $191.6,191.6,117.4$ & $242.1,70.2,91.9$ \\
\hline$a, \beta, \gamma\left(^{\circ}\right)$ & $90,90,120$ & $90,108.5,90$ \\
\hline Resolution $(\AA)^{\text {a }}$ & $50.0-2.25(2.30-$ & $50.0-2.70(2.75-$ \\
\hline Unique reflections a & $\overline{74}, 0799(3,622)$ & $\overline{3} \overline{7}, 826(1,647)$ \\
\hline Redundancy ${ }^{a}$ & $6.4(2.6)$ & $3.5(2.6)$ \\
\hline Completeness (\%) a & $97.4(71.4)$ & $93.3(82.8)$ \\
\hline$<\mathrm{l} / \sigma_{\mathrm{l}}>^{\mathrm{a}}$ & $17.3(1.4)$ & $12.5(1.7)$ \\
\hline$R_{\mathrm{sym}}^{\mathrm{b}}(\%)^{\mathrm{a}}$ & $9.8(44.6)$ & $9.2(56.0)$ \\
\hline$R_{\text {pim }^{\mathrm{b}}}(\%)$ a & $4.0(28.5)$ & $5.5(38.0)$ \\
\hline $\mathrm{CC}_{1 / 2^{\mathrm{c}}}^{\mathrm{c}}(\%)^{\mathrm{a}}$ & $99.4(77.5)$ & $98.4(72.0)$ \\
\hline \multicolumn{3}{|c|}{ Refinement statistics } \\
\hline Resolution $(\AA)$ & $47.9-2.25$ & $49.3-2.70$ \\
\hline Reflections (work) & 70,217 & 33,627 \\
\hline Reflections (test) & 3,821 & 1,791 \\
\hline$R_{\text {cryst }}{ }^{\mathrm{d}} / R_{\text {free }}^{\mathrm{e}}(\%)$ & $17.9 / 22.1$ & 23.6/28.3 \\
\hline No. of atoms & 10,193 & 8,955 \\
\hline Macromolecules & 9,665 & 8,927 \\
\hline Glycans & 28 & 28 \\
\hline Solvent & 500 & - \\
\hline Average $B$-value & 42 & 47 \\
\hline Màacromolecules & 42 & 47 \\
\hline Fab & 40 & 43 \\
\hline RBD & 46 & 57 \\
\hline Glycans & 65 & 113 \\
\hline Solvent & 45 & - \\
\hline Wilson $B$-value $\left(\AA^{2}\right)$ & 37 & 44 \\
\hline \multicolumn{3}{|c|}{ RMSD from ideal geometry } \\
\hline Bond length $(\AA)$ & 0.005 & 0.004 \\
\hline Bond angle $\left({ }^{\circ}\right)$ & 0.78 & 0.67 \\
\hline \multicolumn{3}{|c|}{ Ramachandran statistics (\%) } \\
\hline Favored & 97.8 & 95.5 \\
\hline Outliers & 0.0 & 0.2 \\
\hline PDB code & $7 \mathrm{KN} 3$ & $7 \mathrm{KN} 4$ \\
\hline
\end{tabular}

a Numbers in parentheses refer to the highest resolution shell.

b $R_{\mathrm{sym}}=\Sigma_{h k l} \Sigma_{i}\left|I_{h k l, i}-<l_{h k}>\right| / \Sigma_{h k l} \Sigma_{i} I_{h k l, i}$ and $R_{p i m}=\Sigma_{h k l}(1 /(\mathrm{n}-1))^{1 / 2} \Sigma_{i}\left|I_{h k l, i}-<l_{h k l}>\right| / \Sigma_{h k l} \Sigma_{i} I_{h k l, i}$, where $I_{h k l, i}$ is the scaled intensity of the $i^{\text {th }}$ measurement of reflection $\mathrm{h}, \mathrm{k}, \mathrm{I},\left\langle\mathrm{l}_{h k}>\right.$ is the average intensity for that reflection, and $n$ is the redundancy.

${ }^{c} \mathrm{CC}_{1 / 2}=$ Pearson correlation coefficient between two random half datasets.

${ }^{d} R_{\text {cryst }}=\Sigma_{h k l}\left|F_{0}-F_{c} I / \Sigma_{h k l}\right| F_{0} I \times 100$, where $F_{0}$ and $F_{c}$ are the observed and calculated structure factors, respectively.

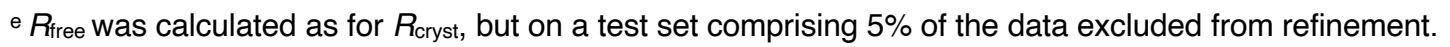


Supplementary Table 2. Hydrogen bonds and salt bridges identified at the antibody-RBD interface using the PISA program*

\begin{tabular}{|c|c|c|c|c|c|c|}
\hline Chain & Residue & Atom & Distance ( $(\AA)$ & Chain & Residue & Atom \\
\hline \multicolumn{3}{|c|}{ S-B8 } & & \multicolumn{3}{|c|}{$\begin{array}{c}\text { SARS-CoV-2 RBD } \\
\end{array}$} \\
\hline \multicolumn{7}{|c|}{ Hydrogen bonds } \\
\hline $\mathrm{H}$ & GLY 26 & $\mathrm{~N}$ & 3.8 & A & TYR 449 & $\mathrm{OH}$ \\
\hline $\mathrm{H}$ & THR 28 & $\mathrm{~N}$ & 2.9 & A & GLN 493 & OE1 \\
\hline $\mathrm{H}$ & THR 28 & $\mathrm{~N}$ & 3.4 & A & SER 494 & OG \\
\hline $\mathrm{H}$ & THR 28 & OG1 & 2.5 & $A$ & SER 494 & $\mathrm{OG}$ \\
\hline $\mathrm{H}$ & GLY 53 & $\mathrm{~N}$ & 2.9 & $\mathrm{~A}$ & GLU 484 & OE1 \\
\hline $\mathrm{H}$ & ASP 54 & $\mathrm{~N}$ & 3.7 & $\mathrm{~A}$ & GLU 484 & OE2 \\
\hline $\mathrm{H}$ & ASN 76 & ND2 & 3.3 & A & TYR 449 & $\mathrm{OH}$ \\
\hline $\mathrm{H}$ & ALA 24 & 0 & 3.9 & $A$ & TYR 449 & $\mathrm{OH}$ \\
\hline $\mathrm{H}$ & LEU 31 & 0 & 3.7 & $A$ & GLN 493 & NE2 \\
\hline $\mathrm{H}$ & SER 32 & OG & 3.0 & $A$ & GLN 493 & NE2 \\
\hline $\mathrm{H}$ & GLU 95 & $\mathrm{O}$ & 2.8 & $\mathrm{~A}$ & TYR 489 & $\mathrm{OH}$ \\
\hline $\mathrm{L}$ & TYR 32 & $\mathrm{OH}$ & 2.7 & $\mathrm{~A}$ & ALA 475 & $\mathrm{O}$ \\
\hline $\mathrm{L}$ & TYR 27d & $\mathrm{OH}$ & 3.7 & $A$ & SER 477 & $\mathrm{O}$ \\
\hline $\mathrm{L}$ & TYR 27d & $\mathrm{OH}$ & 3.7 & $A$ & GLN 474 & NE2 \\
\hline $\mathrm{L}$ & TYR 91 & $\mathrm{O}$ & 3.2 & A & ASN 487 & ND2 \\
\hline \multicolumn{7}{|c|}{ Salt bridges } \\
\hline $\mathrm{H}$ & HIS 33 & NE2 & 3.1 & $\mathrm{~A}$ & GLU 484 & OE1 \\
\hline \multicolumn{3}{|c|}{ S-E6 } & & \multicolumn{3}{|c|}{ SARS-CoV-2 RBD } \\
\hline \multicolumn{7}{|c|}{ Hydrogen bonds } \\
\hline $\mathrm{H}$ & ASN 33 & ND2 & 2.9 & A & ALA 475 & 0 \\
\hline $\mathrm{H}$ & ALA 97 & $\mathrm{~N}$ & 2.8 & $A$ & ASN 487 & OD1 \\
\hline $\mathrm{H}$ & TYR 34 & $\mathrm{OH}$ & 2.9 & $A$ & ASN 487 & ND2 \\
\hline $\mathrm{L}$ & ARG 53 & $\mathrm{NH} 2$ & 2.7 & $A$ & PHE 490 & $\mathrm{O}$ \\
\hline $\mathrm{L}$ & ARG 53 & $\mathrm{NH} 2$ & 3.0 & $A$ & LEU 492 & 0 \\
\hline $\mathrm{L}$ & ARG 53 & NE & 3.7 & $\mathrm{~A}$ & GLN 493 & OE1 \\
\hline $\mathrm{L}$ & TYR 52 & $\mathrm{OH}$ & 3.0 & A & GLN 493 & OE1 \\
\hline $\mathrm{L}$ & ARG 53 & $\mathrm{NH} 2$ & 3.4 & A & GLN 493 & OE1 \\
\hline $\mathrm{L}$ & GLY 68 & $\mathrm{~N}$ & 3.3 & $A$ & ASN 501 & OD1 \\
\hline$L$ & SER 27 & $O G$ & 2.2 & $\mathrm{~A}$ & TYR 505 & $\mathrm{OH}$ \\
\hline$L$ & GLY 29 & $\mathrm{O}$ & 3.1 & $A$ & ARG 403 & $\mathrm{NH} 1$ \\
\hline $\mathrm{L}$ & GLY 29 & $\mathrm{O}$ & 3.2 & A & ARG 403 & $\mathrm{NH} 2$ \\
\hline$L$ & PHE 50 & 0 & 3.2 & $A$ & GLN 493 & NE2 \\
\hline $\mathrm{L}$ & ASP 51 & OD2 & 3.0 & $\mathrm{~A}$ & GLN 493 & NE2 \\
\hline $\mathrm{L}$ & TYR 52 & $\mathrm{OH}$ & 2.7 & $A$ & SER 494 & $\mathrm{~N}$ \\
\hline L & SER 67 & $\mathrm{O}$ & 3.6 & $A$ & ASN 501 & ND2 \\
\hline \multicolumn{7}{|c|}{ Salt bridges } \\
\hline L & ARG 53 & $\mathrm{NH} 1$ & 3.6 & $A$ & GLU 484 & OE1 \\
\hline $\mathrm{L}$ & ARG 53 & $\mathrm{NE}$ & 4.0 & $A$ & GLU 484 & OE2 \\
\hline $\mathrm{L}$ & ARG 53 & $\mathrm{NH} 1$ & 2.5 & A & GLU 484 & OE2 \\
\hline
\end{tabular}

